\title{
Aeolian Dust Forecast in Arid and Semiarid Regions of Peru and Chile and Their Contribution over Particulate Matter Concentration
}

\author{
Albert Salvador ${ }^{1}$, Raúl Arasa ${ }^{1 *}$, Bernat Codina ${ }^{1,2}$ \\ ${ }^{1}$ Technical Department, Meteosim S.L., Barcelona, Spain \\ ${ }^{2}$ Department of Astronomy and Meteorology, University of Barcelona, Barcelona, Spain \\ Email: asalvador@meteosim.com, “rarasa@meteosim.com, bcodina@ub.edu
}

Received 21 December 2015; accepted 26 January 2016; published 29 January 2016

Copyright (C) 2016 by authors and Scientific Research Publishing Inc.

This work is licensed under the Creative Commons Attribution International License (CC BY). http://creativecommons.org/licenses/by/4.0/

(c) (i) Open Access

\begin{abstract}
The dust generated in arid areas of the planet is a very important source of particulate matter in the air, especially favoured by the presence of winds that can raise erodible material from the surface. These particles have an important influence when making an assessment of the air quality, due to its direct and indirect impact on public health. In this work, we reproduce episodes of aeolian dusts in the desert areas of Peru and Chile, where high dust concentration events are common and many mining industries are located. The differentiation of the contribution of particulate matter from Aeolian dusts and mining activities of the area is an important issue, as well as trying to forecast these events. For this purpose, we have calculated an erodibility factor at high resolution that, combined with WRF meteorological output and the GOCART dust scheme, gives the emission of particulate matter. We have introduced the emissions in the photochemical model CMAQ, which determines the concentrations in the different domains, and we have observed that the natural dust contributes greatly to pollution in the area, exceeding permissible limit values in the area of Paracas in Peru, and with contributions of up to $23 \%$ of the total particulate matter in the city of Calama in Chile, resulting non-negligible values for the evaluation of air quality.
\end{abstract}

\section{Keywords}

Air Quality Modelling, WRF-CMAQ, Wind Erodibility, Dust, Mining Industry

\footnotetext{
*Corresponding author.
}

How to cite this paper: Salvador, A., Arasa, R. and Codina, B. (2016) Aeolian Dust Forecast in Arid and Semiarid Regions of Peru and Chile and Their Contribution over Particulate Matter Concentration. Journal of Geoscience and Environment Protection, 4, 128-152. http://dx.doi.org/10.4236/gep.2016.41015 


\section{Introduction}

Air quality is one of the environmental issues that most directly affect the population [1]. The main concern related to air quality is related to their involvement in the health of the population as well as other factors such as, among others, the living conditions of animals and plants [2]. According to the World Health Organization, it is estimated that air pollution affects much of the population, with 2.4 million deaths annually, in addition to material particles, which reduce life expectancy by nine months [3]. In addition, research about the pollution has had in recent years a special interest, especially from the point of view of health [4]. It is important to remark that the emission of gaseous and particulate matter into the atmosphere comes not only from human activity, but also the earth itself (oceans, deserts, forests, etc.) is capable of generating atmospheric pollutants. Among the many ways to define the term of air quality, Monks et al. [5] define it as the measurement of disturbance of the natural state of the atmosphere and the consequences that may entail. In the case of aerosols, they can travel long distances by the wind and for long periods, affecting the health of the area in its path. Similarly, Ki-Hyun et al. [6] state that the particle size is related to its potential in affecting health, being the smaller the most damaging particles.

Especially in arid and semiarid areas, where natural dust is the main source of this particles [7], dust aerosols have a large involvement in the climate system, from a radiative and chemically standpoint., In addition, these emissions limit anthropogenic emissions of some areas of interest that have pollution problems, so that its prediction will be determinant to adapt production to the sanitation of the area [8]. One of the most sensitive areas are the Pacific coastal deserts (mainly Chile and Peru), where natural dust emissions caused by strong winds are more intense. The sandy characteristics of the area favor these events. In South America, we have a complex topography led by the Andes, which affects atmospheric circulation and pollutant transport. Aeolian dust events are often registered in these regions, especially in desert areas like the Atacama Desert in Chile and in the Ica's Department of Peru, where there are also many mining industries.

Chile and Peru have very extensive arid and semiarid regions. These, along with the presence of the mining sector in these with desert regions and activities related to them, such as material transport, have a strong impact on air quality in the area [9]. Some communes in Chile are particularly are some communes in Chile, due to its construction because of nearby mines that drive growth, and in turn are affected by this, as it is the case for example of the communities of Sierra Gorda and Calama, affected by the high levels of pollution. Thus, nearby urban areas are very strong influenced by these elements, making air pollution an important problem to consider. This has caused the governments of Peru and Chile to be concerned about it and has taken steps to try to reduce this impact. Thus, studies of air quality have helped the importance of knowing the contribution of the various sources of pollution in each area towards urban areas.

The contribution of the mining industry is very important in the area of Department of Ica in Peru and Antofagasta region in Chile, making that special measures to control air quality for this sector had been taken [10] [11]. Still, their presence in desert areas makes these also be influenced, especially under episodes of Aeolian dust which bring a lot of aerosols into the environment. Thus providing a forecasting system of these Aeolian dusts in mining areas is a key factor in the proper study of the air quality.

Modeling and forecasting air quality has been used for years, involving both meteorological factors and chemical processes. Models are used for the authorities to assess mitigation measures and obtain an operating forecast [12]-[15]. Mesoscale meteorological models allow us to study and simulate meteorological variables, and photochemical models give us information about how air pollutants disperse in the ambient atmosphere, as well as the air pollutants concentration forecasting.

In this paper, we focus our attention in the use of a photochemical model for the forecasting of Aeolian dust in the Ica's Department of Peru and in the regions of Atacama in Chile, and how to discriminate their contribution against other sources of pollutants as particulate matter, specifically emission sources such as mining industries, as well as elements derived from them like road material transport. With this target, we decided to use an Eulerian coupled air quality modeling system [16], which simulates different processes of trace gases and aerosols. For this purpose, to obtain high-resolution information of the soil characteristics and a well-known study of the area are essential for an efficient air quality modeling system since meteorological outputs are inputs both in the emission and photochemical models. Although the problems of air quality are similar as those observed in developed countries [17]-[19], and other studies have used air quality models [20] for the study over tropical regions, there have been few studies in the area to detect the weight of the influence of natural emissions versus 
anthropogenic emissions.

Description of the studied area is presented in Section 2.1 as well as the methodology for the characterization of the model is presented in Section 2.2. The simulation domains and episodes selected in Section 2.3 and a detailed analysis of the results obtained is presented in Section 3. Finally, some conclusions are reported in Section 4.

\section{Methodology}

In the following sections we show a more detailed description of the studied areas as well as the simulation domains and periods analyzed and the modeling approach.

\subsection{Studied Area}

Following the aim of an Aeolian dust forecasting in arid and semiarid areas of Peru and Chile, the Ica region in Peru and the Antofagasta region in Chile have been chosen to perform the modelling. These two regions have been selected due their location in the coastal desert of Peru and in middle desert of Atacama, respectively.

\subsubsection{Geography and Climate of Peru}

Peru is bordered Ecuador and Colombia to the north, Brazil to the east, Bolivia to the southeast, Chile to the south and the Pacific Ocean to the west. The Andes Mountains run parallel to the Pacific Ocean. To the west, the costa (coast) can be found, which it is a plain that stretches across the country, which is mostly arid. Along the coast you can find sand covered plains that form the deserts of the country, such as Sechura (Piura) and Pisco (Ica). The sierra (highlands) is the region of the Andes. The third region is the Selva (jungle), a flat area that goes to the east of the country, where we find the Amazon rainforest.

The coastal desert of Peru is located in most of the coast of Peru, from north to Piura Tacna and the border with Chile to the south. It is a coastal desert ecoregion with a very arid subtropical climate, high humidity and very little vegetation. It is narrow but it widens greatly in the Departments of Piura and Ica, with a variable width from a few kilometers to $100 \mathrm{~km}$. The temperature of the Peruvian coast is less than that corresponding to latitude because of the cold waters of the Humboldt Current and the barrier caused by the high altitude of the Andes. The coastline is made up of sandy beaches or steep cliffs, dominated by rectilinear forms and few bays.

\subsubsection{Geography and Climate of Chile}

Chile is bordered by Peru to the north, Argentina to the east, Bolivia to the northeast and the Drake Passage in the far south. Chile's topography includes the central depression, which is surrounded by two mountain ranges that cover most of the country with the Andes on its eastern border and the Cordillera de la Costa on its western side. It is between the Cordillera de la Costa and the Pacific where some of the most important cities and ports of the country are located, thanks to the coastal plains.

The Atacama Desert is a plateau mainly located on northern Chile. It's the driest non-polar desert in the world, with contact with the coastline of the Pacific. With an approximate area of $105.000 \mathrm{~km}^{2}$, it expands southward to a few kilometers above the city of Copiapo, bringing Chilean cities like Antofagasta and Calama a strong influence by the presence of this desert. At an altitude of between 400 and 1500 meters above sea level, the climate of this region, besides having in mind its presences on the Tropic of Capricorn, is strongly influenced by the Humboldt Current, an ocean current caused by the rise of deep, cold waters, which limit evaporation in the area, causing a strong aridity and the presence of rare and light rain. These conditions favor, in the presence of strong winds, Aeolian dust events.

Once introduced the studied areas, we provide information regarding the mining activities in the areas, both the mining industry and other related activities such as mining material transport by road.

The introduction of this section is due to the great importance of the mining industry in the area, one of the main drivers in the economy of both countries, and the damages suffered due to, among others, the problems contributions of pollutants caused by natural soil erosion by wind.

\subsubsection{Mining Features in the Studied Area of Peru}

The region of Ica in Peru is a chosen location with great weight in the mining industry, not so much from the point of view of location of mines, but with a prominent role in managing the material produced there and ma- 
terial which is required, particularly in the field of transport, by road and by sea.

The Terminal Portuario General San Martín, also known as port of Pisco, is a seaport of goods which over the past year has been much modernized to meet local and international cargo, to support growth in demand for port services in its area of influence. The project seeks to position the port of Pisco as an important spot of southern Peru as well as for it to be able to mobilize more than 2.5 million tons of cargo and 81.500 TEU (20-foot containers). In November 2013, the port had a marginal wharf of 700 meters with 4 berths, of which only two of them were working.

The seaport is located in the Bay of Paracas, in the Punta Pejerrey in the Paracas Peninsula. The port activity is of great importance in fisheries and agro-industrial activities, metallurgy and mining in the area. The expansion of the port of Pisco would enable producers to cut time and costs by reducing the need for $250 \mathrm{~km}$ of truck transport to Lima's port of Callao.

In Pisco, we can find steelworks as Aceros Arequipa and tin smelters as Minsur's Funsur. Considering a larger region, in Ica's region we can find the zinc-lead mine Milpo’s Cerro Lindo, Shougang's Hierro Perú iron ore mine and iron ore projects being developed by Jinzhao Mining and Junefield. In this way, the demand is growing, so the objective of this project is to attract what is produced in the region, which has traditionally been sent to the port of Callao, with its high management costs, reducing their competitiveness.

In Figure 1, we can see the closer road map of the region studied and its surroundings. It can also be seen the location of some of the most important mining industries of the area and, at the same time, as most of them have in their respective proximity one of the main roads of the country, making the transport by road of mining material a very important factor among other means of transporting mining equipment such as railway transport. Some of these mines near the region are Antapite, San Genaro and Cerro Lindo, which are in production or in the process of enlargement. In turn, they are also under exploration projects as Luishaja, Hallazgo, Josjo, Pukaqaqa, and Liscay.

Unfortunately, in the region of Peru considered we have not weather stations that allow us to validate both meteorological and particulate concentration data, so it would be interesting to have the appropriate infrastructure for this purpose.

\subsubsection{Mining Features in the Studied Area of Chile}

The city of Calama is located in the Antofagasta region in the province of El Loa in northern Chile, near a mining region and the Atacama Desert. In the mining region are located some mines, all owned by the Chilean

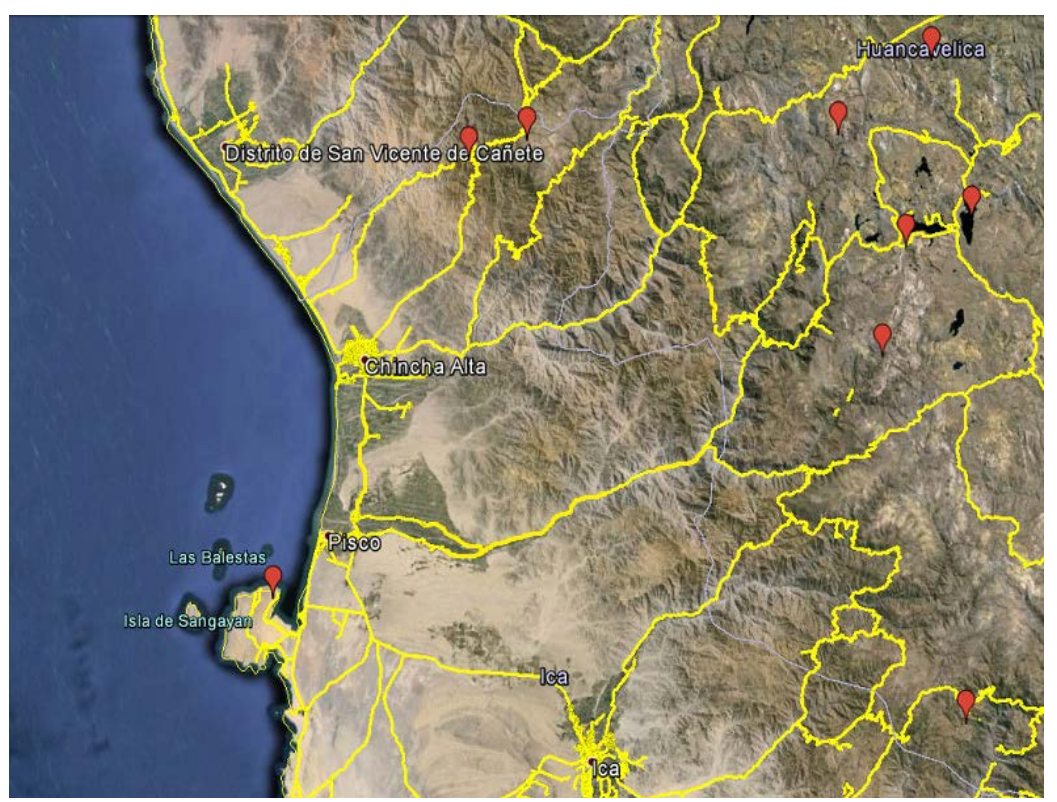

Figure 1. Road map and the location of nearest mining industries of the regions of Ica and Huancavelica. On the peninsula of Paracas the Terminal Portuario General San Martin is located [Image generated using Google Earth]. 
state-owned Codelco, as Radomiro Tomic, Chuquicamata, Mina Sur, Ministro Hales, as well as the casting Codelco Norte and the dam of tailings Talabre.

With an important mining tradition since its colonization, in the early twentieth century began the time of the Great Copper Mine in Chile, with the exploitation of mines like Chuquicamata, Potrerillos and El Teniente. The Chuquicamata case, for example, involved the construction of cities in its area, in this case the city of Chuquicamata. In 2007, its inhabitants moved to the city of Calama for the expansion of the mine, realizing the great importance that these mines take place in the region, making Calama a bedroom community. In fact, Calama is the commune with more resources generated from copper mining in Chile, national economic pillar, producing $22.2 \%$ of the total national production. Furthermore, Chile is the largest copper producer in the world, increasing its contribution of 14\% of world production in 1960 to 36\% in 2006.

Codelco is currently conducting a structural and strategic project called Underground Chuquicamata Mine, with the intention of creating an underground operation that allows to exploit some of the resources that lie under the current site as it is considered that this will no longer be profitable within the next decade.

In Figure 2, we can see the closer road map of the region studied and its surroundings. Calama major roads are Ruta 24 and Ruta 25. The first communicates Calama with the port of Tocopilla, intersecting with the Pan American route at $70 \mathrm{~km}$. The Ruta 25 connects the city with the port of Antofagasta. This route passes through other points of interest such as the communes of Sierra Gorda and Baquedano. In addition, this is most commonly used because it connects other routes, having access to the communication between the ports of Antofagasta and Santos (Brazil).

We have been provided with data from a study conducted in the same defined domain of Calama [16]. With it we know the emissions profile of the region. In this profile are considered different emission sources, the majority of them from industries of copper, with a contribution of a $43 \%$ of the total particulate material emission, and suspended dust as a result of mining operations, with a contribution of a $37 \%$ of the total particulate material emission.

We also have in the case of Calama weather stations provided by the Ministerio del Medio Ambiente of Chile, mostly within the city, to make studies of particle concentration and evolution of the wind and other meteorological parameters, like temperature and relative humidity. In our case we used the stations Colegio Pedro Vergara Keller, Complejo Deportivo 23 de Marzo and Estación Centro, as can be seen in Figure 3.

\subsection{Modeling Approach}

We have used an Eulerian coupled modeling system (WRF-ARW/AEMM/CMAQ) to evaluate the impact of natural dust over particulate matter concentration. The mesoscale meteorological model used is Weather Research and Forecasting-Advanced Research (WRF-ARW) version 3.3 [21]. Air Emission Model of Meteosim (AEMM v3.0) [13] [22] is a numerical, deterministic, Eulerian, local-scale model developed by Meteosim S.L. It allows to obtain the intensity of emissions in different areas, either anthropogenic (traffic, industry, residential,

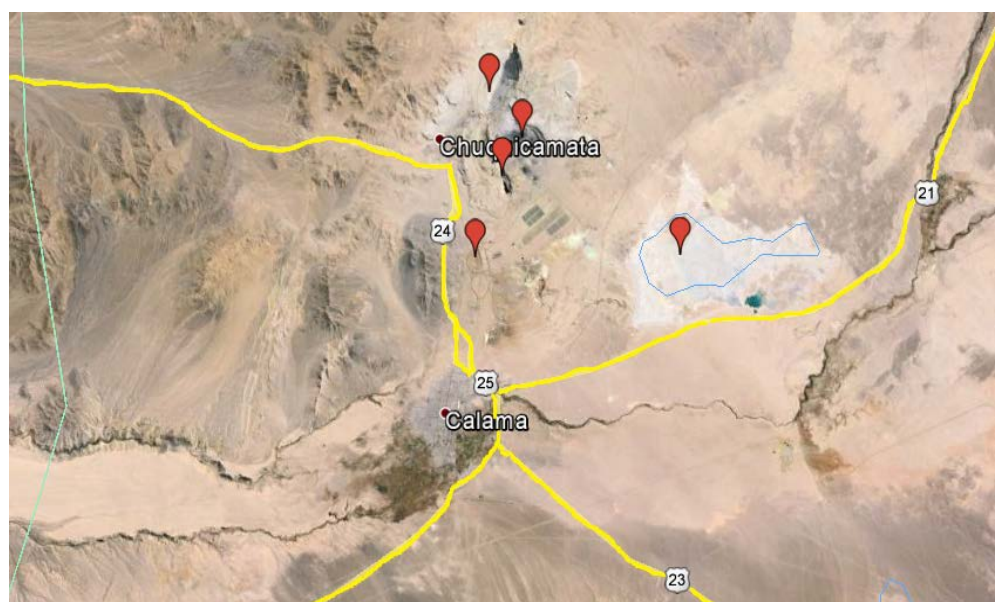

Figure 2. Road map and the location of nearest mining industries of the region of Calama [Image generated using Google Earth]. 


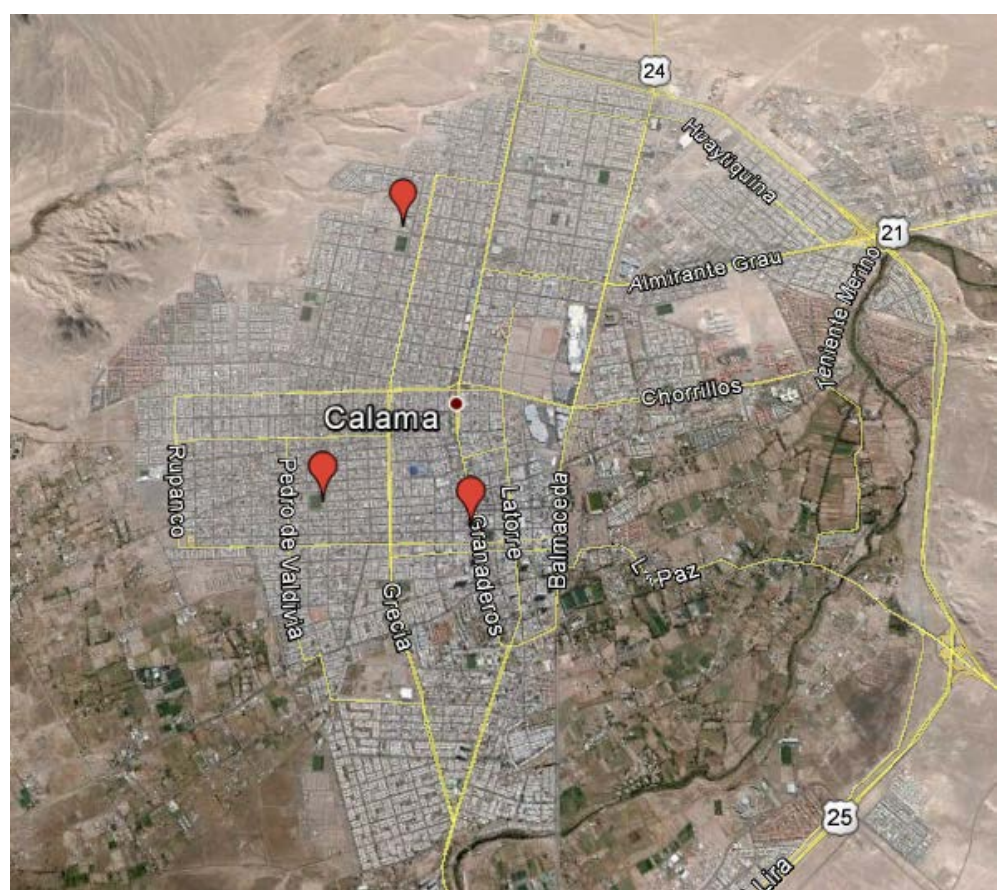

Figure 3. Map of Calama with the three stations used to assess concentrations of $\mathrm{PM}_{10}$ in the city marked. All of the data is provided by the Ministerio del Medio Ambiente of Chile. On the top Colegio Pedro Vergara Keller, left Complejo Deportivo 23 de Marzo and Estación Centro in the center [Image generated using Google Earth].

etc.) or natural (emissions caused by vegetation or erosion dust) for the area of interest. And the U.S. Environmental Protection Agency models-3/CMAQ model is the one used to simulate the physical and chemical processes into the atmosphere [23]. CMAQ is an open-source photochemical model which is updated periodically by the research community. In this contribution we use CMAQ v4.7.1, considering CB-5 chemical mechanism and associated EBI solver [24], and AERO5 aerosol module [25].

For each of the selected days we have run numerical simulations for 48 hours, leaving the first 24 hours as a spin-up to minimize the consequences of taking into account the initial conditions for the start of simulation. The vertical structure of the model includes 32 vertical layers, where the first 20 levels are inside atmospheric boundary layer and the domain top is about $100 \mathrm{hPa}$.

\subsubsection{Erosion Dust Parameterization}

In order to calculate emissions of natural dust, it has been carried out a literature review to determine which are the possible parameterizations to take for such purpose. Thus we have chosen some of the most commonly parameterization used, describe its operation, and finally choose one of them depending on the data that is available. In this way, there are different ways to calculate the flow of particulate material that is raised by action of wind on the surface. The first is the parameterization of Marticorena and Bergametti [26]:

$$
F= \begin{cases}\alpha C u_{* s}\left(u_{* S}^{2}-u_{* t}^{2}\right) & \text { if } u_{* S}>u_{* t} \\ 0 & \text { if } u_{* s} \leq u_{* t}\end{cases}
$$

where $C$ is an empirical proportionality dimensional constant, $\alpha$ is an efficiency factor of sand flow which depends on the clay content of the soil, $u_{* s}$ is the friction velocity and $u_{* t}$ is the limit friction velocity from which the wind is able to start lifting the erodible material from the soil.

Another possible parameterization is the implemented by Shaw et al. [27], which is a derivative of the parameterization of Marticorena and Bergametti but with some modifications. This parameterization follows the DUSTRAN (Dust Transport Model) scheme and calculates the dust emission flux as: 


$$
F= \begin{cases}\alpha C u_{*}^{4}\left(1-\frac{f_{w} u_{* t}}{u_{*}}\right) & \text { if } u_{*}>u_{* t} \\ 0 & \text { if } u_{*} \leq u_{* t}\end{cases}
$$

where $C$ is an empirical proportionally constant, $\alpha$ is the vegetation mask accounting for vegetation type effect, $u_{*}$ is the friction velocity, $u_{* t}$ is the threshold friction velocity the limit friction velocity from which the wind is able to start lifting the erodible material from the soil, and $f_{w}$ is the soil wetness factor for soil moisture effect.

In this work we have implemented the Goddard Global Ozone Chemistry Aerosol Radiation and Transport (GOCART) dust scheme, widely used by international organizations such as NOAA and NASA, and developed by the latter, to simulate atmospheric aerosols, $\mathrm{CO}$ and sulfur gases. Basically, the GOCART dust scheme attempts to relate wind speed with erodibility of the area to finally determine dust emissions at each location. This scheme follows the parameterization of Ginoux et al. [28], giving us the emission flux aerosol particle:

$$
F_{p}= \begin{cases}\operatorname{CSs}_{p} u_{10 m}^{2}\left(u_{10 m}-u_{t}\right) & \text { if } u_{10 m}>u_{t} \\ 0 & \text { otherwise }\end{cases}
$$

where $C$ is an empirical proportionality dimensional constant equal to $1 \mu \mathrm{g} \cdot \mathrm{s}^{2} \cdot \mathrm{m}^{-5}, S$ is the erodibility, $u_{10 m}$ is the horizontal wind speed at 10 meters, $u_{t}$ is the threshold velocity, and $s_{p}$ is the fraction of each size class, which has a dependence with the particle size. So, the $s_{p}$ values are thus 0.1 for the class $0.1-1 \mu \mathrm{m}$, and $1 / 3$ for the classes 1 - $1.8 \mu \mathrm{m}, 1.8$ - $3 \mu \mathrm{m}$ and 3 - $6 \mu \mathrm{m}$, respectively. Constant $C$ is an empirical proportionality constant, as described above, originally estimated based on regional datasets. In this work, we fixed this constant $C$ to the value $0.5 \mu \mathrm{g} \cdot \mathrm{s}^{2} \cdot \mathrm{m}^{-5}$ as in Cavazos-Guerra et al. [20]. In the case of $u_{t}$ threshold velocity, the interparticle cohesion forces modifies its value, which depends essentially on the particle size and the surface wetness, as gives the following equation:

$$
u_{t}= \begin{cases}A \sqrt{\frac{\rho_{p}-\rho_{a}}{\rho_{a}} g \Phi_{p}}\left(1.2+0.2 \log _{10} w\right) & \text { if } w<0.5 \\ \infty & \text { otherwise }\end{cases}
$$

where $A=6.5$ is a dimensionless parameter, $w$ is the surface wetness, $\Phi_{p}$ is the particle diameter, $g$ is the acceleration of gravity and $\rho_{p}$ and $\rho_{a}$ are the particle and air density, respectively. Using the parameters of Corine Land Cover of soil moisture depending on land use, and the size of the particles in the different areas, it has given a threshold speed of $3 \mathrm{~m} / \mathrm{s}$ in the region of Peru and $1.5 \mathrm{~m} / \mathrm{s}$ in the region of Chile.

In the domains of study we have calculated the ability (or ease) of soil to be eroded by influence of surface wind. Soil erodibility estimates the amount of sand exposed at the surface to be eroded by the wind, and the subsequent formation of aeolian dusts. Erodibility expression is extracted from the following equation [28]:

$$
S=\left(\frac{Z_{\max }-Z_{i}}{Z_{\max }-Z_{\text {min }}}\right)^{5}
$$

where $S$ is the probability to have accumulated sediments in the grid cell $i$ of altitude $Z_{i}$, and $Z_{\max }$ and $Z_{\min }$ are the maximum and minimum elevations in the surrounding $1^{\circ} \times 1^{\circ}$ topography, respectively. To increase the topographic contrast of these areas, Ginoux et al. [28] took the relative altitude at the fifth power. Only bare soil land surface can be considered as a possible dust source as not exhibit protection against the wind, making the wind erosion to be optimal in these surfaces. The choice of assuming a constant area of $1^{\circ} \times 1^{\circ}$ is based on the surrounding hydrological basin. In general, the deeper the depression is, the higher the probability of sediments accumulation will be.

\subsubsection{Erodibility in the Studied Area}

The topographic data of the analyzed regions have been obtained from the USGS (United States Geological Survey) at a spatial resolution of 3" × 3" (approximately 90 meters). As it has been said, the erodibility surface affected corresponds exclusively to a particular type of soil, so land use information of the chosen domains is 
obtained at a spatial resolution of 300 meters, and a filter by the particular soil type is set in the erodibility map, giving for example values of null erodibility on surfaces covered by water, vegetation covered surfaces, etc. To understand more clearly the concept of applying a filter with the information of land use in the area, we have changed the Equation (5) slightly:

$$
S=\left(\frac{Z_{\text {max }}-Z_{i}}{Z_{\text {max }}-Z_{\text {min }}}\right)^{5} \cdot B S
$$

where $B S$ is a dimensionless parameter value with the percentage content of bare soil of the area in terms of land use, with 1 being a completely barren terrain and 0 without content of bare soil. In Figure 4, we show the modified erodibility factor $S$ calculated for the regions analysed.

In the parameterization of the erodible material which is emitted to the atmosphere from the flux Equation (3), we have considered that $45 \%$ of coarse particulate matter $(2.5-10 \mu \mathrm{m})$ and fine particulate matter (smaller than $2.5 \mu \mathrm{m}) 5 \%$, fixing a relationship between them by $90 \%$ and $10 \%$, respectively, in terms of emissions. For the rest of particles larger than $10 \mu \mathrm{m}$ of radius, CMAQ model dismisses and does not consider them in its algorithms [29].

Additionally, one of the factors for which we are interested in the study of pollution by particles, in addition to the air quality problems, is for the issues associated with visibility. Known as the smog effect of the concentration of pollutants, especially in big cities and industrial areas. This haze is especially caused by small particles, absorbing sunlight, and reducing visibility, making that a high concentration of particulate material can significantly reduce the maximum visible distance, decreasing the security in terms of transport.

\subsubsection{Model Evaluation}

Because we have meteorological records in the city of Calama, as we have introduced above, we have evaluated the meteorological model on the meteorological stations to highlight the values of calculated pollutants concentrations. In this way, we have been applied the approach of comparing measurements with model results through different statistics.

For the evaluation of temperature and relative humidity, we introduce the statistical MAGE (Mean Absolute Gross Error) as:

$$
\text { MAGE }=\sum_{i}^{N} \frac{|D|}{N}
$$

and for the evaluation of wind speed, we introduce the statistical RMSE (Root-Mean-Square-Error) as:

$$
\mathrm{RMSE}=\sqrt{\frac{1}{N} \sum_{i}^{N} D^{2}}
$$

where $D$ is the difference between modelled values and observed ones, and $N$ is the total number of measurements.
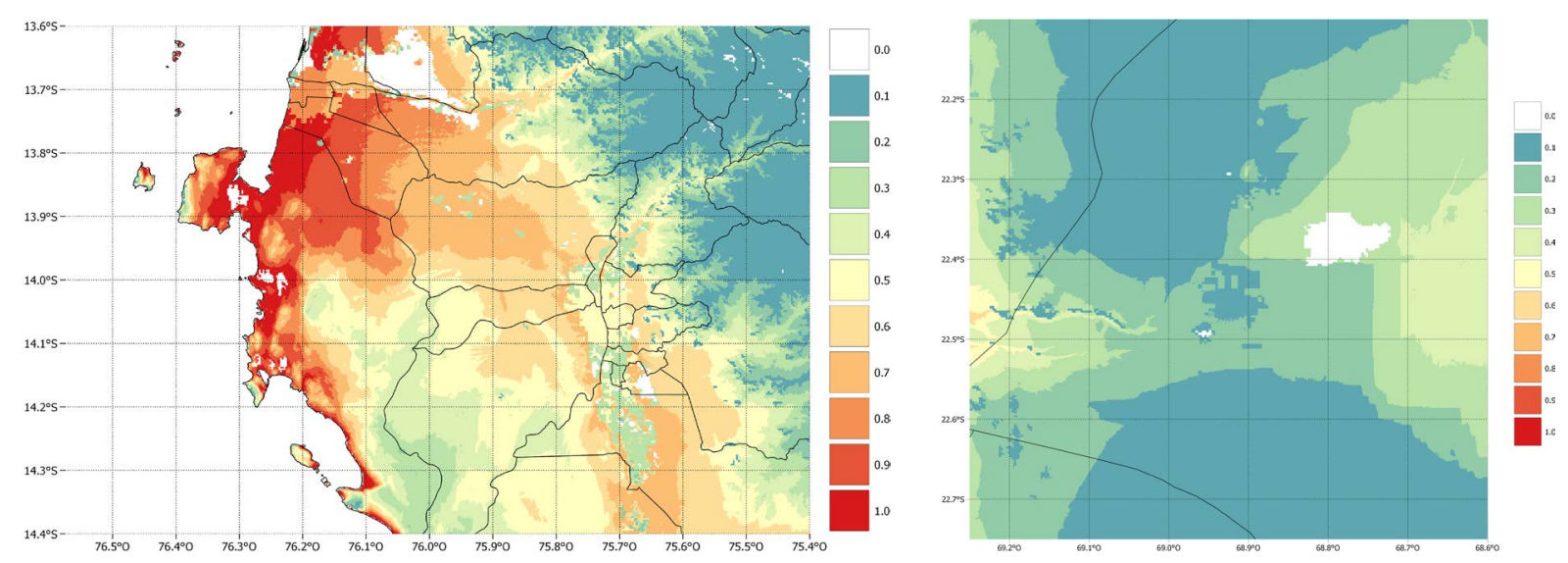

Figure 4. Modified erodibility factor calculated for the region of Ica (left) and Calama (right). 
The benchmark is accorded following Emery and Tai [30] suggestions, with a value of $2 \mathrm{~K}$ for the temperature MAGE, 20\% for the relative humidity MGE and $2 \mathrm{~m} / \mathrm{s}$ for the wind speed RMSE.

Finally, to assess the accuracy of the model wind measurements of the weather stations assessed, we have used a new parameter introduced by Santos-Alamillos et al. [31] for analyzing the accuracy of the wind direction estimates: the directional accuracy (DACC) parameter. For angles $\alpha$ and $\beta$, the circular distance is defined as:

$$
\Delta \theta(\alpha, \beta)=\min \left[\alpha-\beta, 360^{\circ}-(\alpha-\beta)\right]
$$

The DACC is defined as the percentage of times in which the circular distance between the observed and modeled wind direction is lower than a threshold, chosen as $30^{\circ}$ :

$$
\text { DACC }=\frac{\sum_{0(\text { else })}^{1\left(\text { (if } 0 \leq \Delta \theta_{i} \leq 30^{\circ}\right)}}{N} \times 100
$$

When we compare the values of pollutant concentration in the city, we use the IOA (Index of Agreement) developed by Willmott [32] as a standardized measure of the degree of model prediction error and varies between 0 and 1 . A value of 1 indicates a perfect match, and 0 indicates no agreement at all. The IOA value is introduced as:

$$
\mathrm{IOA}=1-\frac{\sum_{i}^{N}(o b s-\operatorname{sim})^{2}}{\sum_{i}^{N}(|\operatorname{sim}-\overline{o b s}|+|o b s-\overline{o b s}|)^{2}}
$$

where obs and sim are the observed and modelled values, respectively, and $\overline{o b s}$ is the mean of the observed values.

\subsection{Simulated Domains and Episodes Selected}

In Figure 5, we show modeling domains used for the simulations. The coupled air quality modeling is built over a mother domain (D01) with $27 \mathrm{~km}$ spatial resolution centered at $18.3^{\circ} \mathrm{S}, 69.8^{\circ} \mathrm{W}$. It comprises almost all the territory of Peru, Bolivia, part of Brazil, Paraguay, the northern and central territory of Chile and Argentina, as well as some part of Uruguay. Part of other countries as Ecuador and Colombia are partially considered too. We have tried to consider an important part of the Pacific Ocean as well as the terrain of the territory. In Table 1, detailed information can be found.

In one of the two regions considered, the first nested domain (D02), with a spatial resolution of $9 \mathrm{~km}$, covers the central and southern territory of Peru and part of the Pacific Ocean. Inside of it we can find again two new nested domains D03 and D04, with a spatial resolution of $3 \mathrm{~km}$ and $1 \mathrm{~km}$ respectively. The domain D03 covers completely the Department of Ica and part of the Departments of Lima, Huancavelica, Ayacucho and Arequipa as well as some part of the Pacific Ocean. Finally, the domain D04 covers the region around the district of Para-

\begin{tabular}{|c|c|c|c|c|}
\hline Domain & Description & Resolution & Grid points & Domain size \\
\hline D01 & Central-western South America & $27 \times 27 \mathrm{~km}^{2}$ & $137 \times 137$ & $3699 \times 3699 \mathrm{~km}^{2}$ \\
\hline D02 & Central and south Peru & $9 \times 9 \mathrm{~km}^{2}$ & $127 \times 127$ & $1143 \times 1143 \mathrm{~km}^{2}$ \\
\hline D03 & Ica region & $3 \times 3 \mathrm{~km}^{2}$ & $130 \times 112$ & $390 \times 336 \mathrm{~km}^{2}$ \\
\hline D04 & Ica/Pisco/Paracas & $1 \times 1 \mathrm{~km}^{2}$ & $133 \times 97$ & $133 \times 97 \mathrm{~km}^{2}$ \\
\hline D05 & North Chile & $9 \times 9 \mathrm{~km}^{2}$ & $82 \times 82$ & $738 \times 738 \mathrm{~km}^{2}$ \\
\hline D06 & Antofagasta region & $3 \times 3 \mathrm{~km}^{2}$ & $64 \times 64$ & $192 \times 192 \mathrm{~km}^{2}$ \\
\hline D07 & Calama & $1 \times 1 \mathrm{~km}^{2}$ & $64 \times 64$ & $64 \times 64 \mathrm{~km}^{2}$ \\
\hline
\end{tabular}
cas, considering the cities of Paracas, Ica and Pisco.

Table 1. Simulation domains. 

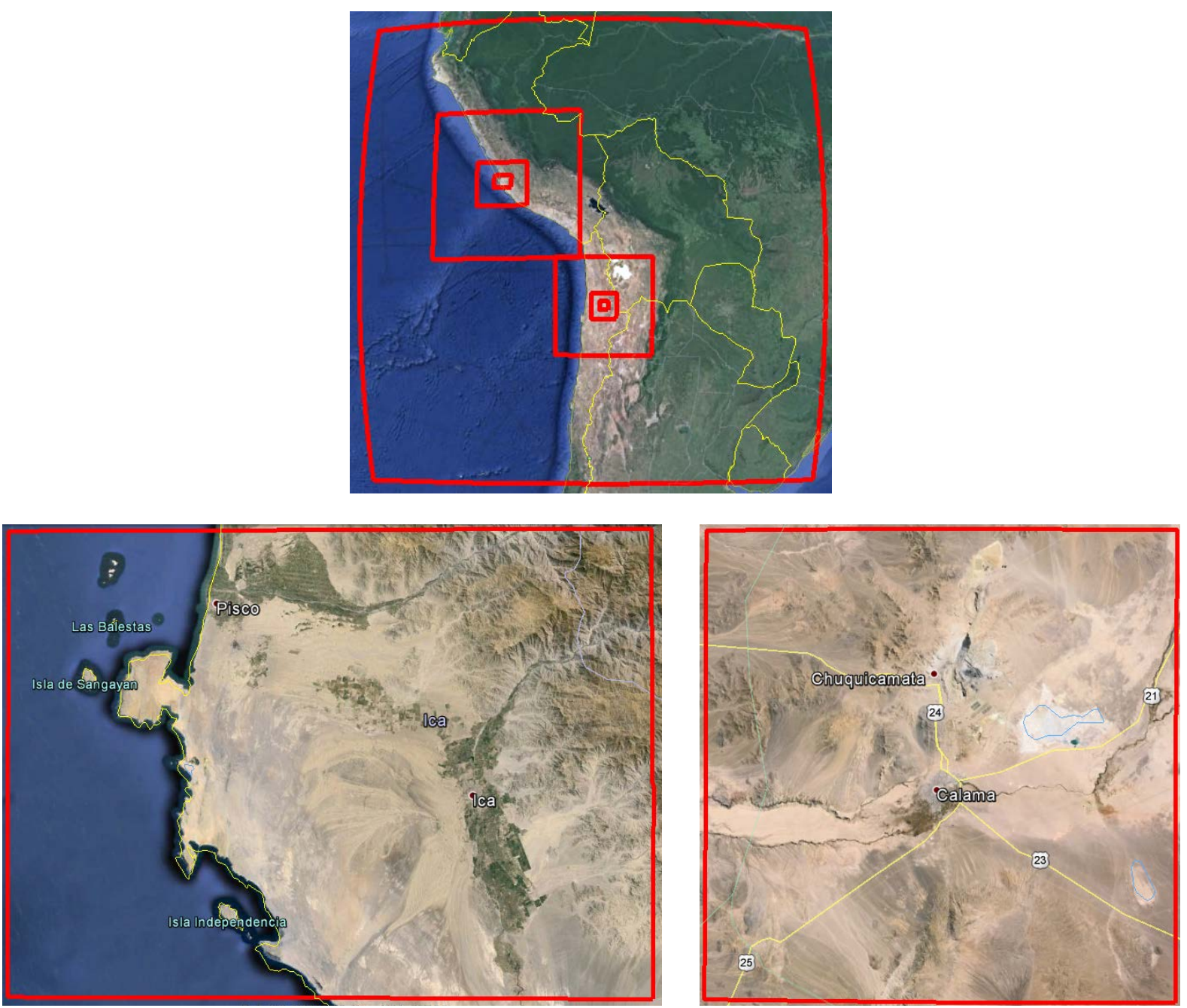

Figure 5. Modelling domains for simulation (top). Domains D04 (bottom left) and D07 (bottom right) [Images generated using Google Earth].

In the second region considered, the second nested domain (D05), with a spatial resolution of $9 \mathrm{~km}$, covers the northern territory of Chile and part of the Pacific Ocean, as well as part of Bolivia and Argentina, considering the topography of the area. Inside of it we can find two new nested domains D06 and D07, with a spatial resolution of $3 \mathrm{~km}$ and $1 \mathrm{~km}$ respectively. The domain D06 covers the Antofagasta region, and the domain D07 cover the region around the municipality of Calama, in the region of Antofagasta.

Our goal is to detect and simulate recorded episodes of aeolian dust in the two indicated domains, to determine the feasibility of the model. In this way, simulations have been conducted in two different days, each one for the two different regions considered. In this case, for the region of Peru we have chosen an episode of Aeolian dust in the Department of Ica, around the municipalities of Paracas and Pisco, and for Chile we have chosen an episode of aeolian dust around the municipality of Calama. Episodes have been selected based on the news which talk about them, extracted from the local press.

In the case of Peru, the presence of Vientos Paracas, common winds in the area, lifted sand of the surface causing an aeolian dust in the area between the municipalities of Pisco, Paracas and Ica, the capital of the studied department. On February 23rd of 2015 was recorded in Pisco upper winds at $54 \mathrm{~km} / \mathrm{h}$, reducing visibility to 100 meters (Source: laprensa.peru.com, rpp.com.pe).

In the case of Chile, we have chosen this area because, despite not having a high component of erodibility by the wind effect, there are records of pollutants due to other factors, such as anthropogenic emissions in the area, and a small component of natural pollution can help to overcome the limit values allowed in critical regions. 
Additionally, on November 18th of 2013 strong winds were recorded in the area, with records of up $70 \mathrm{~km} / \mathrm{h}$ in the districts of Sierra Gorda and San Pedro de Atacama, causing visibility problems (Source: soychile.cl).

\section{Results and Discussion}

\subsection{Peru}

\subsubsection{Meteorological Analysis}

The meteorological situation during February 23rd of 2015 in Peru has been modeled with the WRF-ARW model and it has been compared with the situation described by the press.

In Figure 6, we can see the weather situation a higher domain than we will work then. In it we see the change in pressure between 12 UTC on February 23rd and 00 UTC on the following day. We can also observe the module and wind direction for this domain.

We can detect that the situation is similar among them, unable to detect a significant change with the passing hours. The left half of both images shows a situation of prevailing winds from the south, solidary with the pressure contrast between the maritime area and the coastal area, leaving the lower pressure values at the right of the shift of the wind, as expected. We also noted that offshore wind regime has no big swings, being the closest to the coast which are influenced by this and have a slight twist direction, tracing the coast and even introduced into it.

In the image corresponding to 00 UTC we can detect that above the region of Paracas and Pisco has appeared a low pressure situation. This has been matched by an increase in wind speed in the area, as well as a steeper inclination of the wind direction, being more perpendicular to the coast.

If we observe the evolution of temperatures at 2 meters in Figure 7, we find that, as the day progresses, the air temperature increases as expected due to the radiation received from the sun. From 12 UTC, we note that the temperatures begin to rise due to the rising of the sun, warming the surface in general, especially near the coast and a few kilometers inland. Thus, we can see that, near the region of Paracas and Pisco, there is a temperature of between 22 and 24 Celsius at 12 UTC, to a temperature between 32 and 34 Celsius at 20 UTC in the area Paracas and northeast of the city of Pisco. Similarly, temperatures in inland areas also suffer a significant increase from the same time interval from 18 to 28 Celsius in most of the region. In the northeastern part of the area studied, a predominantly mountainous area, temperatures do not undergo a major change, remaining between about 14 and 10 Celsius during the day.

It is interesting to compare this evolution with the evolution of the pressure at sea level in the region. In Figure 8, we can see this evolution. We note that in most of the region, mainly in the coastal and interior area, regardless of the mountainous area, the sea level pressure has little variation between 1012 and $1011 \mathrm{hPa}$. Along the time, we can see that in the area around Pisco and northeast of Paracas, it forms a low pressure situation which causes a decrease of up to $1009 \mathrm{hPa}$, with a variation of up to $2 \mathrm{hPa}$ in 30 kilometers. We can find this deeper change between Pisco and the Paracas Peninsula, an area that will be of interest. At the same time, with the pass of time this situation is gradually normalized, increasing the pressure.
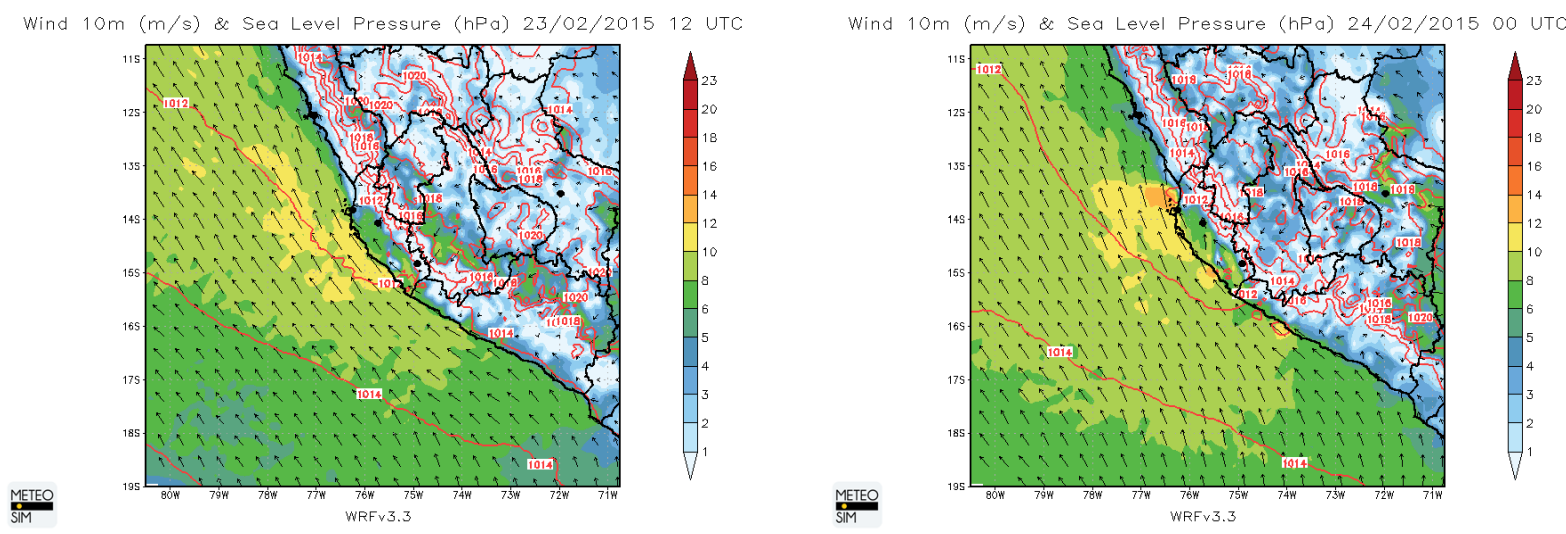

Figure 6. Sea level pressure and wind speed between 12 UTC (left) and 00 UTC (right) for the region of Peru. Arrows indicate the direction of the wind at 10 meters high. 

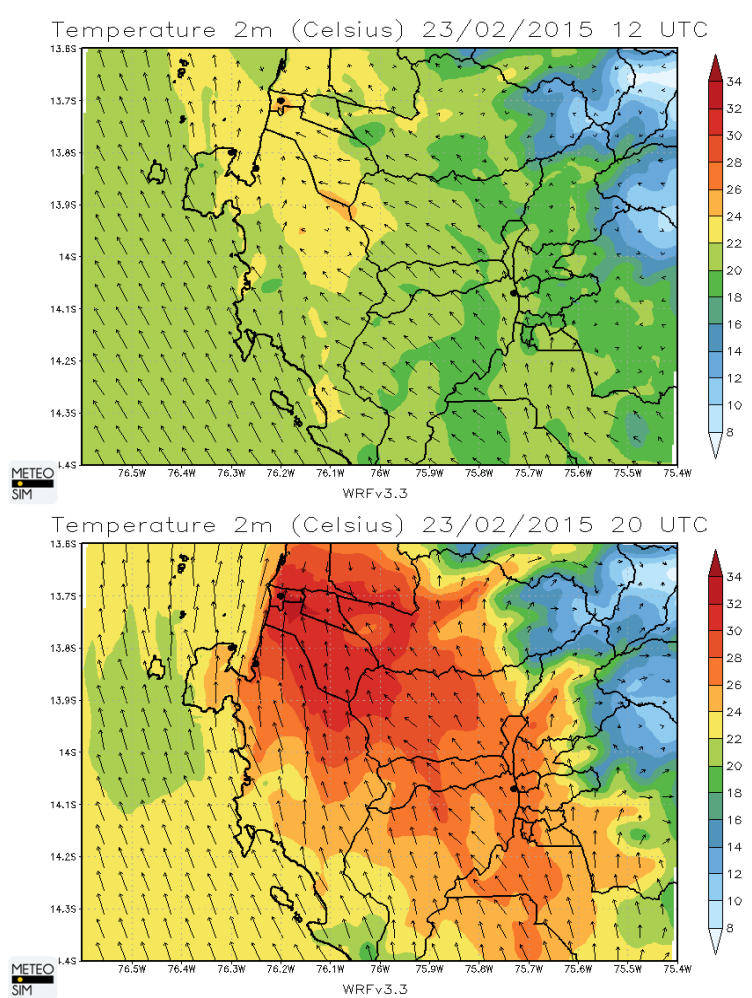
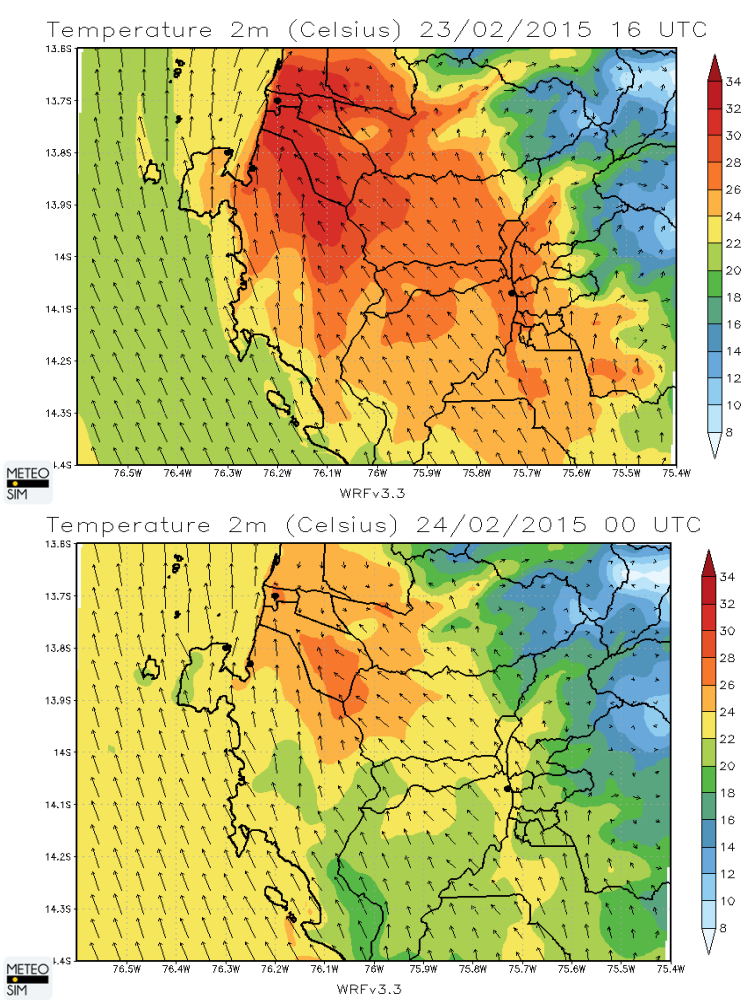

Figure 7. Temperature at 2 meters between 12 UTC (top left corner) and 00 UTC (bottom right corner) at 4 hour interval for the region of Ica. Arrows indicate the direction and the wind module at 10 meters high.
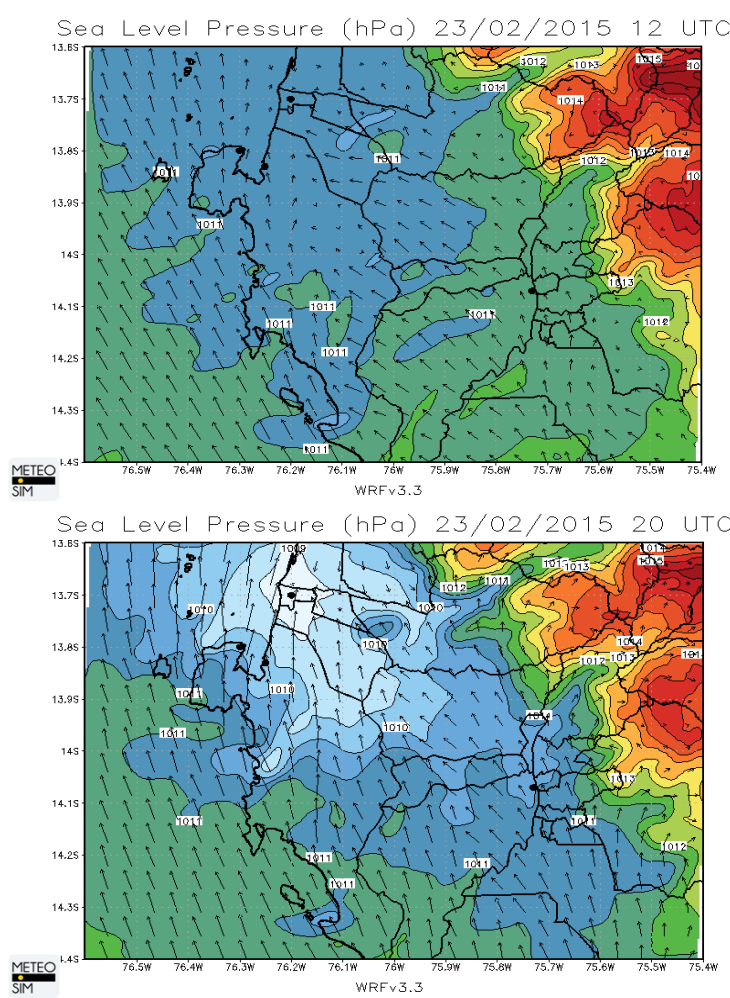
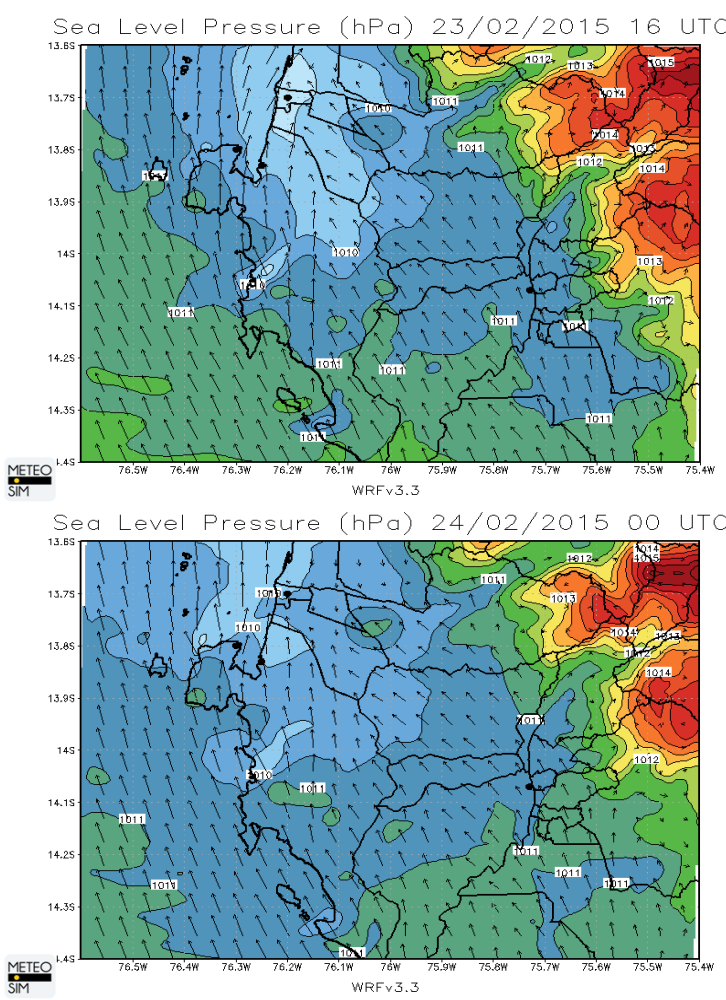

Figure 8. Mean sea level pressure between 12 UTC (top left corner) and 00 UTC (bottom right corner) at 4 hour interval for the region of Ica. Arrows indicate the direction and the wind module at 10 meters high. 
This situation is caused by the significant increase in temperature experienced by the region, especially in the region near Pisco. The increase in surface temperature generates that the surface air rises due to convection. This result in decreased surface pressure directly, and can cause pressure wells as the situation that has occurred. The pressure drop is widespread throughout the not mountainous area, but the biggest drop was in an area where the temperature gradient is greater, around the area of Pisco, causing the areas where the temperature has a smaller gradient, the pressure variation is also lower.

In Figure 9, we can see the evolution of the module and direction of the wind in the region. Here we can see how initially the region has a situation of southerly winds between 10 and $5 \mathrm{~m} / \mathrm{s}$ near the southern coast of the region, taking a smaller contrast on the north coast of the region, where winds exceed very slightly $4 \mathrm{~m} / \mathrm{s}$, and even with calm wind areas. The entire northeast region has a calm wind situation and in inland areas the wind takes a direction towards the north west with intensities of up to $10 \mathrm{~m} / \mathrm{s}$.

Around 16 UTC we see how the wind strength has increased considerably, especially on the north coast of the region, which has undergone a transition from near calm winds to intensities of up to $15 \mathrm{~m} / \mathrm{s}$. Still, the strongest winds can be found a few kilometers further down, about 15 kilometers south of the Paracas Peninsula, where the wind reaches speeds of up to $17 \mathrm{~m} / \mathrm{s}$, affecting the high intensity winds a small area.

At 20 UTC, winds reach a maximum speed in the north of the Paracas Peninsula with speeds of up to $18 \mathrm{~m} / \mathrm{s}$. From this moment there is a drop in wind strength, while remaining at high speeds.

If we compare this situation with the evolution of the sea level pressure, we can see that there is a high correspondence, noting that the higher wind intensities are where the pressure gradient was also higher, making also that the direction of the wind goes direct to the lower pressure, trying to counter the situation.

\subsubsection{Pollution Analysis}

At this point, we analyze the situation of $\mathrm{PM}_{10}$ pollution in the area. In Figure 10, we can see the daily value of $\mathrm{PM}_{10}$ concentration in the studied area. Due to the laws of the country against contaminants, is considered an
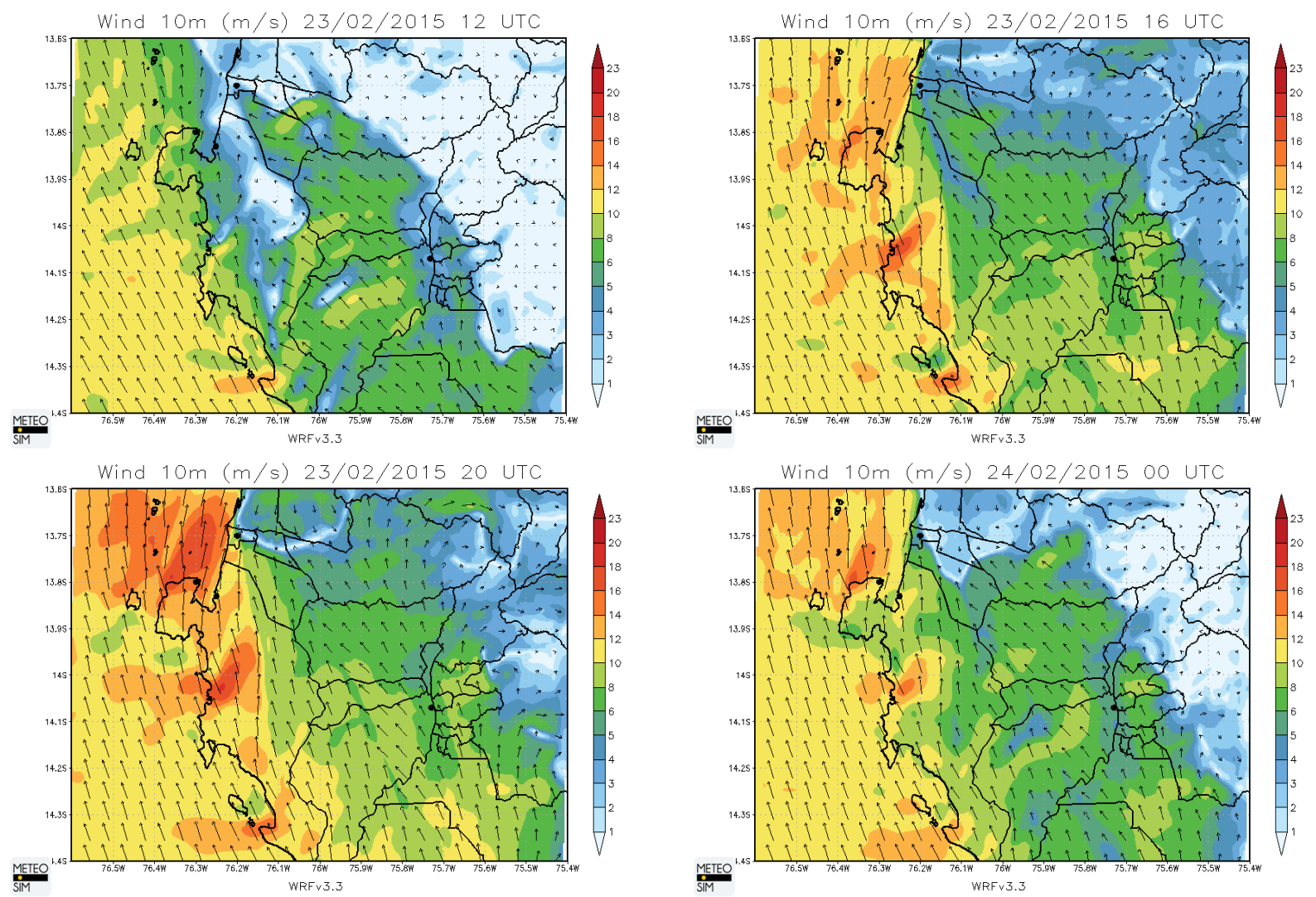

Figure 9. Wind speed and direction at 10 meter high between 12 UTC (top left corner) and 00 UTC (bottom right corner) at 4 hour interval for the region of Ica. 


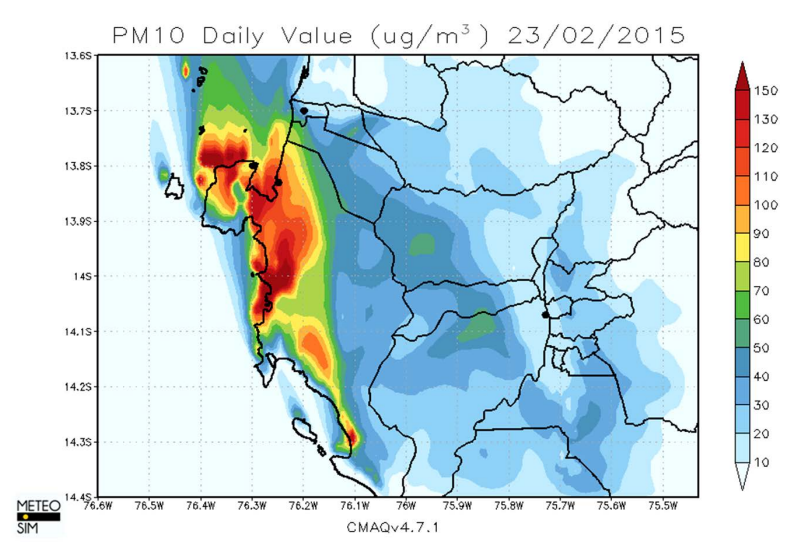

Figure 10. $\mathrm{PM}_{10}$ daily value map from natural dust for the region of Ica.

excess of the permitted limit values for $\mathrm{PM}_{10}$ when these exceed $150 \mu \mathrm{g} / \mathrm{m}^{3}$ [33]. As a result, we can observe different locations where the contribution of natural dust overpass these limits, such as for example some points of the north of the Paracas Peninsula and about $15 \mathrm{~km}$ south of Paracas. In addition, although the contribution of natural dust does not exceed the limit value in other locations of the territory, especially near the coast, the values remain high, so it should take into account a consideration of the activity that occurs there that can produce $\mathrm{PM}_{10}$ contaminant, adapting to the situation for not to aggravate pollution.

We have also calculated the average ratio on the area between the concentration of coarse particulate matter (2.5 - $10 \mu \mathrm{m}$ ) and fine (smaller than $2.5 \mu \mathrm{m}$ ), considering only natural emissions. Thus, it is estimated that the relationship between coarse and fine particulates is about $87 \%$ and $13 \%$, respectively. Thus we can determine the relationship between the two groups of particles has remained approximately constant $(90 \%$ and $10 \%)$ respect of its emissions.

We remember that the Terminal Portuario General San Martín, also known as port of Pisco, is located at the northeast of the Paracas Peninsula. In Figure 11, we can see an evolution of $\mathrm{PM}_{10}$ concentration there throughout the day.

In it we can see both the behaviour the concentration has had throughout the day and the daily average value over the same period. We can see that during the first hours the values are between 65 and $80 \mu \mathrm{g} / \mathrm{m}^{3}$.

From 12 UTC, when a minimum concentration is reached, it begins to rise continuously, reaching $110 \mu \mathrm{g} / \mathrm{m}^{3}$ around 18 UTC. Thereafter, the concentration remains around these high values. The height of the planetary boundary layer remains at a height of between 100 meters for most of the day, reaching the 350 meters during the last hours of the day. The low height of the planetary boundary layer is due to be in a coastal area, with slight variations in temperature throughout the day. Thus, we can see that there is not a direct correlation between the height of the planetary boundary layer and the concentration of pollutants, with the maximum concentration to be found when the planetary boundary layer is higher, contrary to plan. This is due to the great influence of the wind with the transport of pollutants, which makes the concentration of particles to increase, even despite the slight increase in planetary boundary layer height. Thus, the port of Pisco daily value reaches $83 \mu \mathrm{g} / \mathrm{m}^{3}$, far from the $150 \mu \mathrm{g} / \mathrm{m}^{3}$ limited by the pertinent laws, but a high enough value to be taken into account when taking relevant reduction measures from other emissions, in order to prevent that the final daily value is not exceeded.

In Figure 12, we can see a daily evolution of the vertical profile of concentration of $\mathrm{PM}_{10}$ from natural sources in the port of Pisco.

Here we can see the height reached by the contribution of natural dust. Thus, we can determine that during the first hours the dust cloud, with a dust concentration over $30 \mu \mathrm{g} / \mathrm{m}^{3}$, can be seen at a height between 400 and 200 meters. From 12 UTC, the dust begins to rise rapidly to a maximum height around 20 UTC, reaching a dust concentration of $30 \mu \mathrm{g} / \mathrm{m}^{3}$ at an altitude of 1200 meters. It is also from 12 UTC when the concentration at the surface begins to rise, as we have observed in the previous figure.

Due to the wind is declining on the last hours of the day, the height of the dust cloud also gradually decreases to finally reach the level that has been maintained during the first hours of the studied day.

Both this dust cloud height as the high concentration of $\mathrm{PM}_{10}$ on surface, especially during the last hours of the day, should make us aware that these will entail difficulties, both from a standpoint of air quality problems 


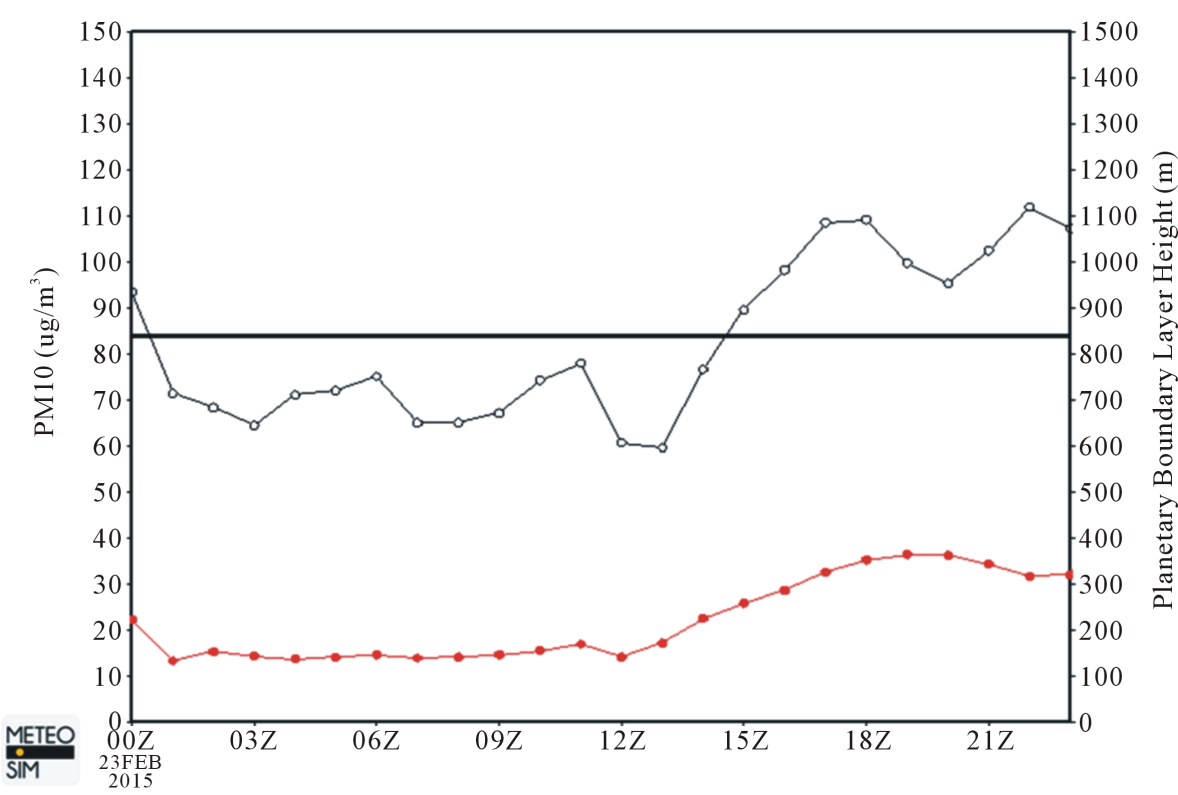

Figure 11. Evolution of $\mathrm{PM}_{10}$ concentration value (black) and planetary boundary layer height (red) on the port of Pisco. The horizontal black line indicates the daily value for this location.

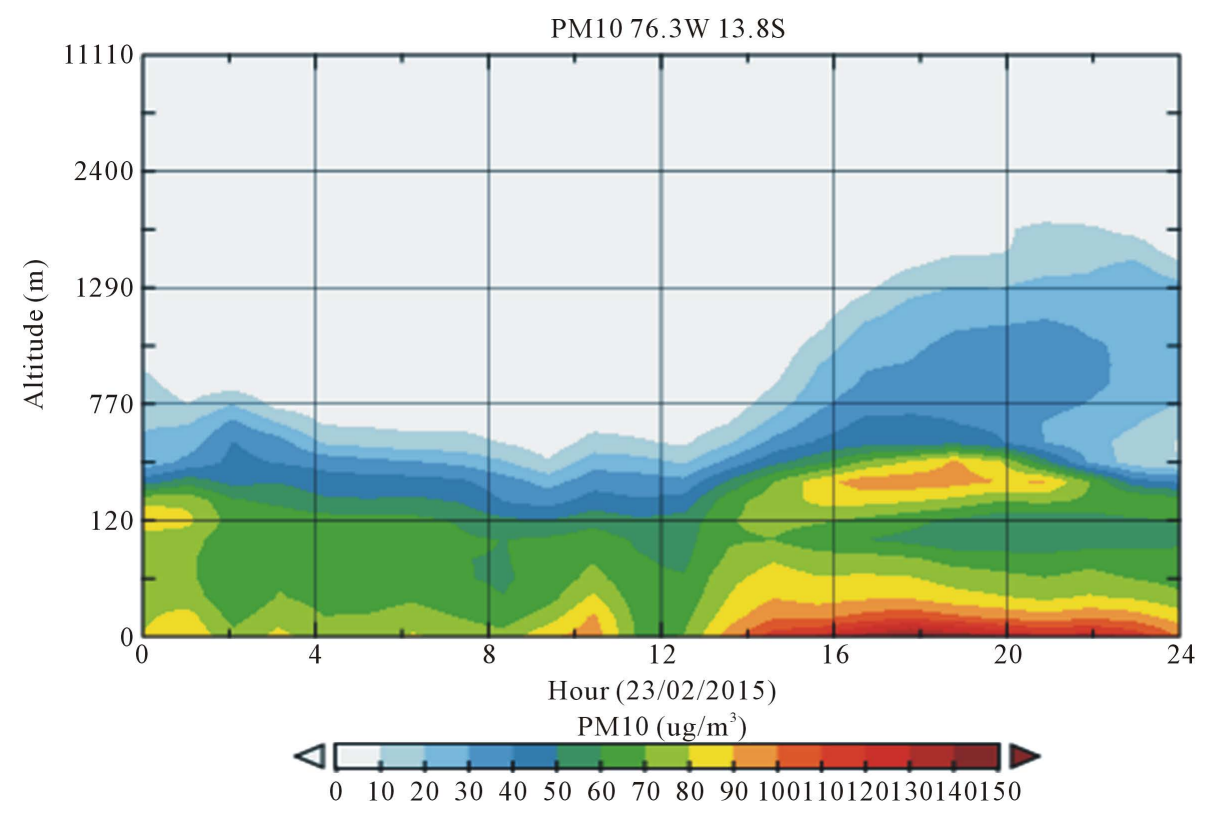

Figure 12. Evolution of $\mathrm{PM}_{10}$ vertical profile concentration value from natural dust on the port of Pisco.

as well as visibility problems. The latter particularly affects the management of the port of Pisco and the transport of mining material from the nearest mining industries, with special attention to road transport.

We must also take into account the visibility variability, closely related to the concentration of particulate matter, which obtains the minimum values when the concentration is maximum. In extreme cases, visibility can be reduced to 100 meters.

This factor is considered very important when assessing all means of transport because it will be very affected by the loss of visibility and reduce transport security significantly. Furthermore, we must bear in mind that this high-altitude cloud of dust contributes to a large displacement of the particles in suspension, being able to move 
tens of kilometers with the wind in its wake increasing the concentration of pollutants.

\subsection{Chile}

\subsubsection{Meteorological Analysis}

The meteorological situation during November 18th of 2013 in Chile has been modelled with the WRF-ARW model and it has been compared with the situation described by the press.

In Figure 13, we can highlight the synoptic meteorological situation in the studied area. Here we can see the evolution of the pressure and wind direction and module from 12 UTC on November 18th until 00 UTC on 19th.

Synoptically we cannot detect any noticeable change in the general conditions of pressure. Initially the wind is predominantly from the south into the sea and near the coast, although with little intensity and even points of calm. Entering into the territory, in west-central domain winds have more intensity, taking a direction towards east.

Late in the day we see that the situation at sea has not changed, despite a slight increase in wind strength at south of the peninsula of Mejillones. West and south of Calama can see how the wind has taken a direction towards the south and southeast respectively, and western winds domain have generally increased in intensity, while still maintaining the same direction as a few hours ago.

In Figure 14, we can see the evolution of the temperature to 2 meters from the region near Calama for November 18th. We initially observe that at about 12 UTC the temperature is quite homogeneous in the area around 11 Celsius, with lower temperatures in the north and slightly higher on the southwest of the domain. While day temperatures have markedly increased, reaching 21 Celsius at southwest of Calama at 16 UTC and up to 23 Celsius at around 20 UTC. Thereafter and with the sunset, temperatures begin to fall throughout the domain.

In Figure 15, we can analyze how the sea level pressure has evolved and try to relate it to the temperature variations of the area.

We can see how initially the pressure in the region remains homogeneous around $1013 \mathrm{hPa}$. Quickly we see how the pressure decreases in general throughout the territory to reach mainly around $1011 \mathrm{hPa}$ and forming a pressure pit on the southwest of Calama, reaching the $1009 \mathrm{hPa}$.

This situation continues for several hours, without descending more the sea level pressure but increasing the area affected by the pressure pit slightly. Until 00 UTC pressure has again increased considerably throughout the region, keeping the pressure pit on the southwest of Calama, albeit with a smaller involvement area and higher pressures.

If we relate the evolution of temperature with the sea level pressure, we can see that we can describe a similar relationship to which we have discussed above in the situation that hit the region of Ica in Peru. The rising temperatures generate a rising of the mass of air from the surface, lowering the pressure, causing pressure drops more pronounced where temperatures had increased more significantly.

Finally, in Figure 16, we find the evolution of the module and wind direction in the region. Here we can see
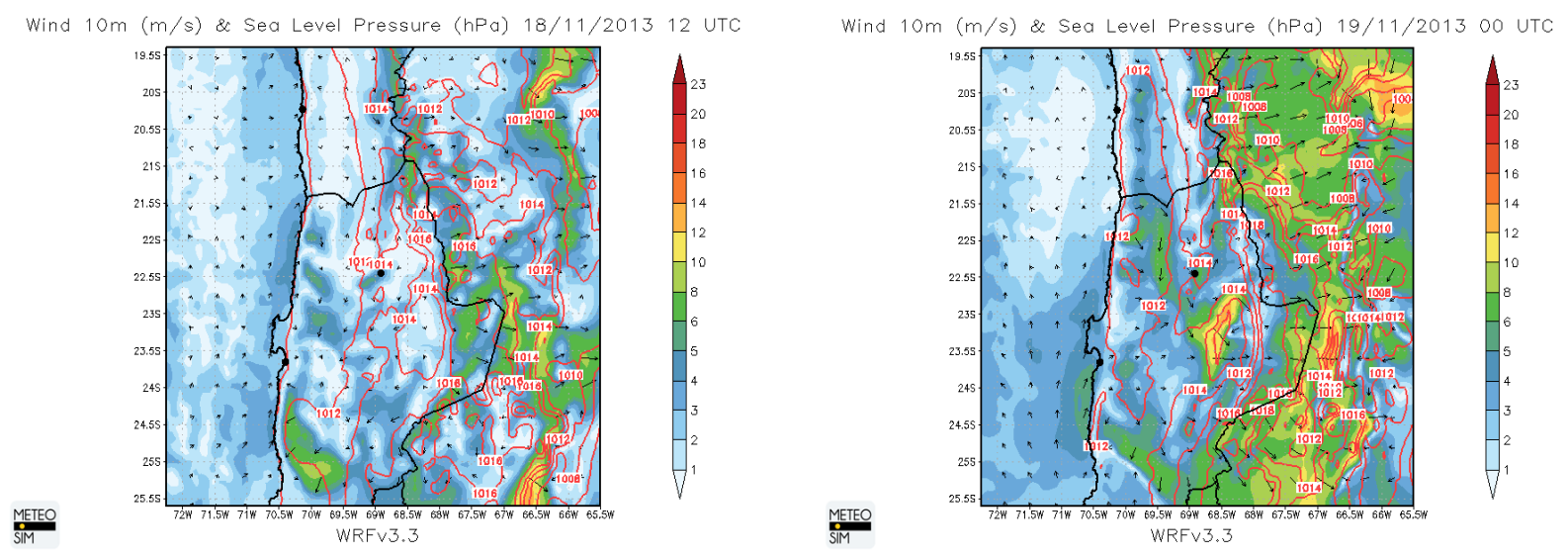

Figure 13. Sea level pressure and wind speed between 12 UTC (left) and 00 UTC (right) for the region of Chile. Arrows indicate the direction of the wind at 10 meters high. 

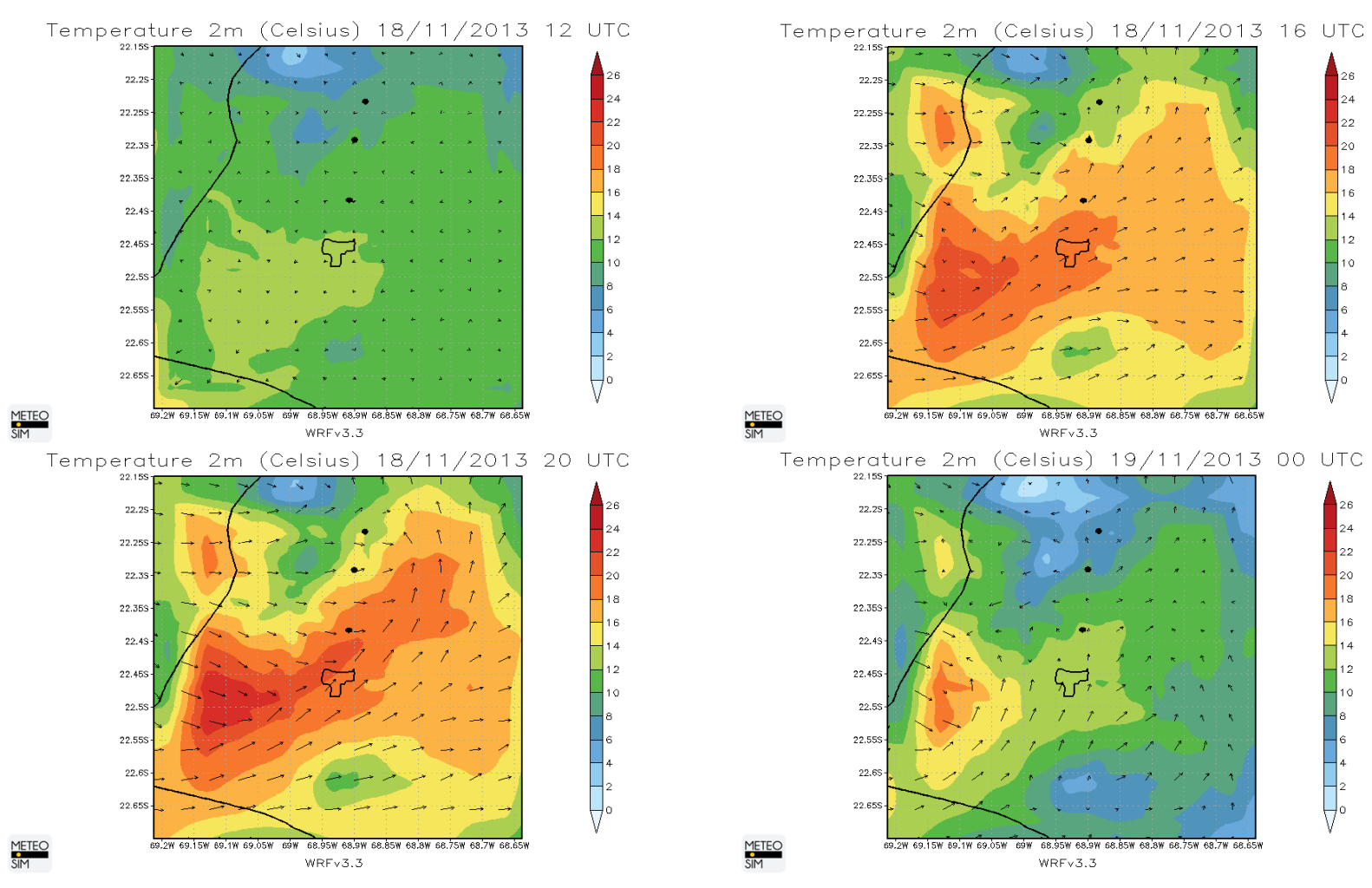

Figure 14. Temperature at 2 meters between 12 UTC (top left corner) and 00 UTC (bottom right corner) at 4 hour interval for the region of Calama. Arrows indicate the direction and the wind module at 10 meters high.
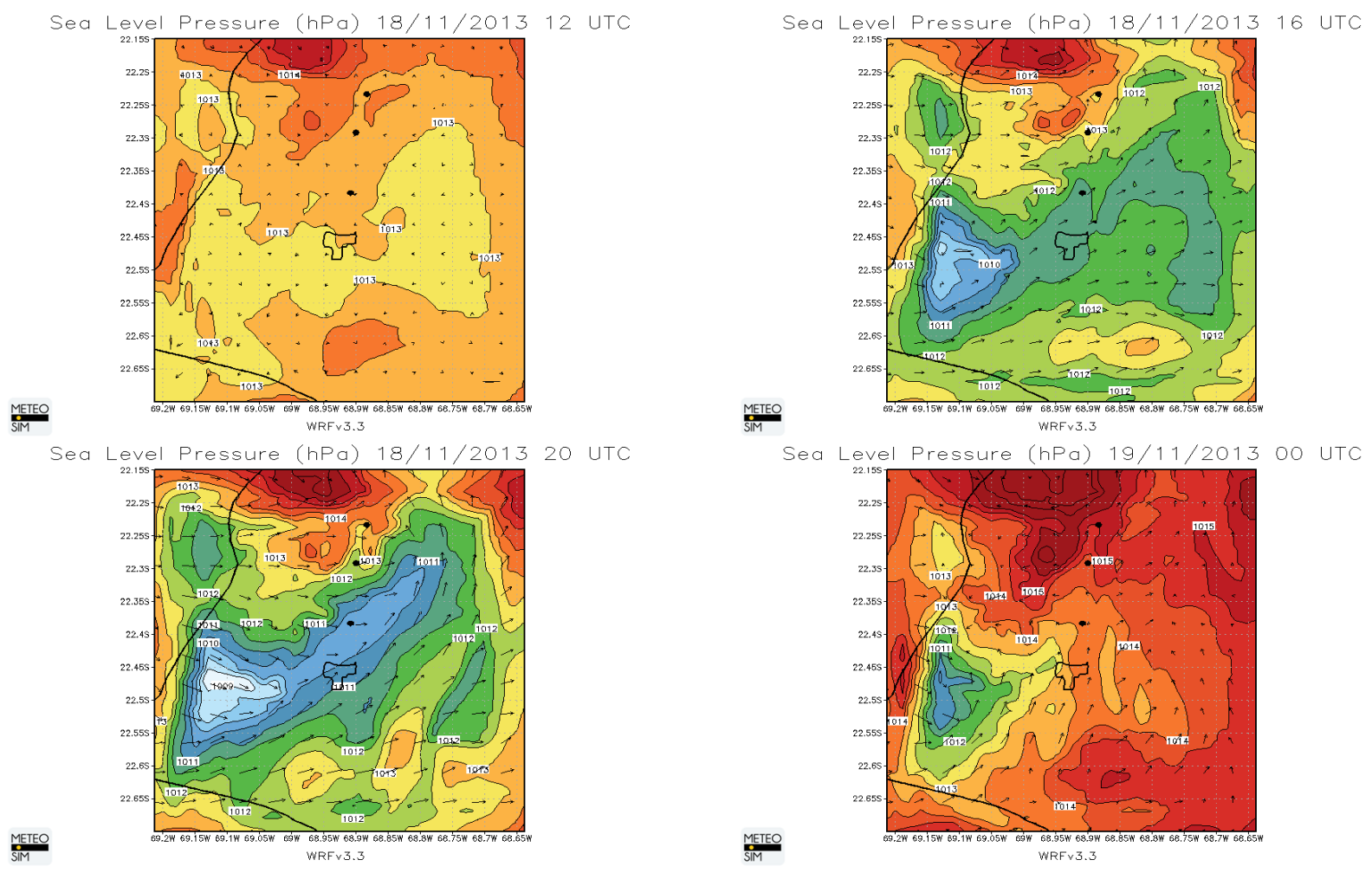

Figure 15. Mean sea level pressure between 12 UTC (top left corner) and 00 UTC (bottom right corner) at 4 hour interval for the region of Calama. Arrows indicate the direction and the wind module at 10 meters high. 

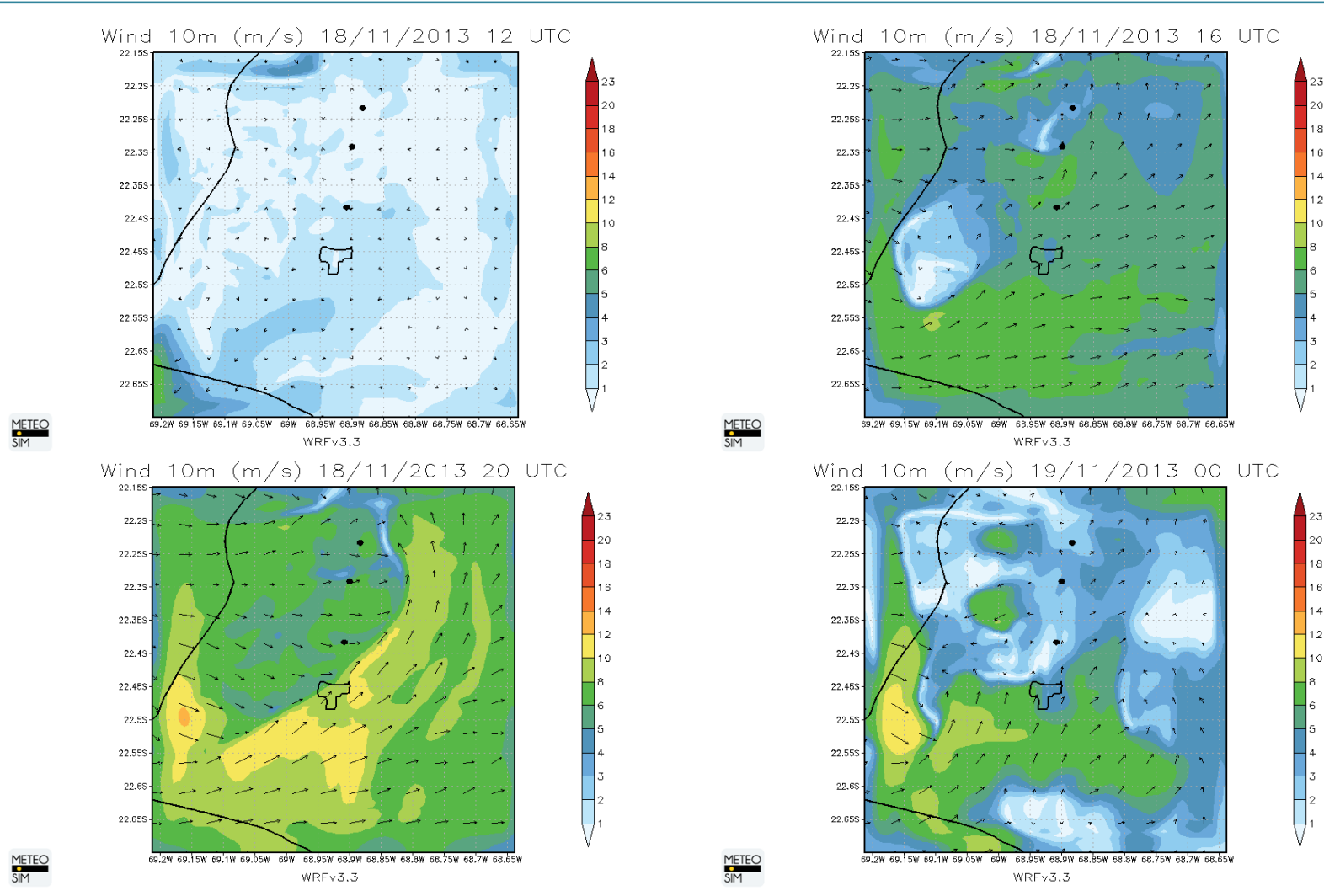

Figure 16. Wind speed and direction at 10 meter high between 12 UTC (top left corner) and 00 UTC (bottom right corner) at 4 hour interval for the region of Ica.

that at 12 UTC winds are almost calm, increasing its intensity over hours.

Around 16 UTC winds begin to reach $6 \mathrm{~m} / \mathrm{s}$ with a strong component in the direction towards the northeast, with only one component to the east in the northwest area. Around 20 UTC we have the same situation as a few hours ago, but with a higher intensity winds, especially on southwest of Calama, where winds slightly exceed 10 $\mathrm{m} / \mathrm{s}$.

In the evening, the winds have dropped significantly in the north and east of the domain, with some points of moderate intensity in southwest of Calama.

Looking at both this map and the evolution of the pressure we detect that higher winds have been recorded where the pressure drop is more pronounced. In this same way, we can note that the wind direction is toward lower pressures and, when reached, it runs parallel to the isobars, trying not to cross them, and reducing its intensity when the pressure gradient increases again.

Once the weather situation is described by the model, we found interesting to compare the measures of wind, temperature and relative humidity, both from those predicted by the model and from the measures in weather stations described in the Methodology section. In this way, in Figure 17, we can observe the wind roses both from model output on bottom and stations measures on top.

We can say that the DACC value in the city of Calama is calculated as approximately a $45 \%$. This value is reasonable due to the small number of wind measurements on which to work, so that with a study over a longer period it would be easier to give better values. Furthermore, the DACC value also has an inherent importance to topography, changing the values of the model with respect to the measured, reducing the value of the parameter [31].

In Table 2, we can see the statistical evaluation for temperature, relative humidity and wind speed for the city of Calama. If we compare their errors with the recommendation values, relative humidity is within the benchmark. Although temperature and wind speed are not within the benchmark, they are not so far and, for the same reason for the DACC value, a longer period would be easier to give better values, but they are far good for the following pollution analysis. 

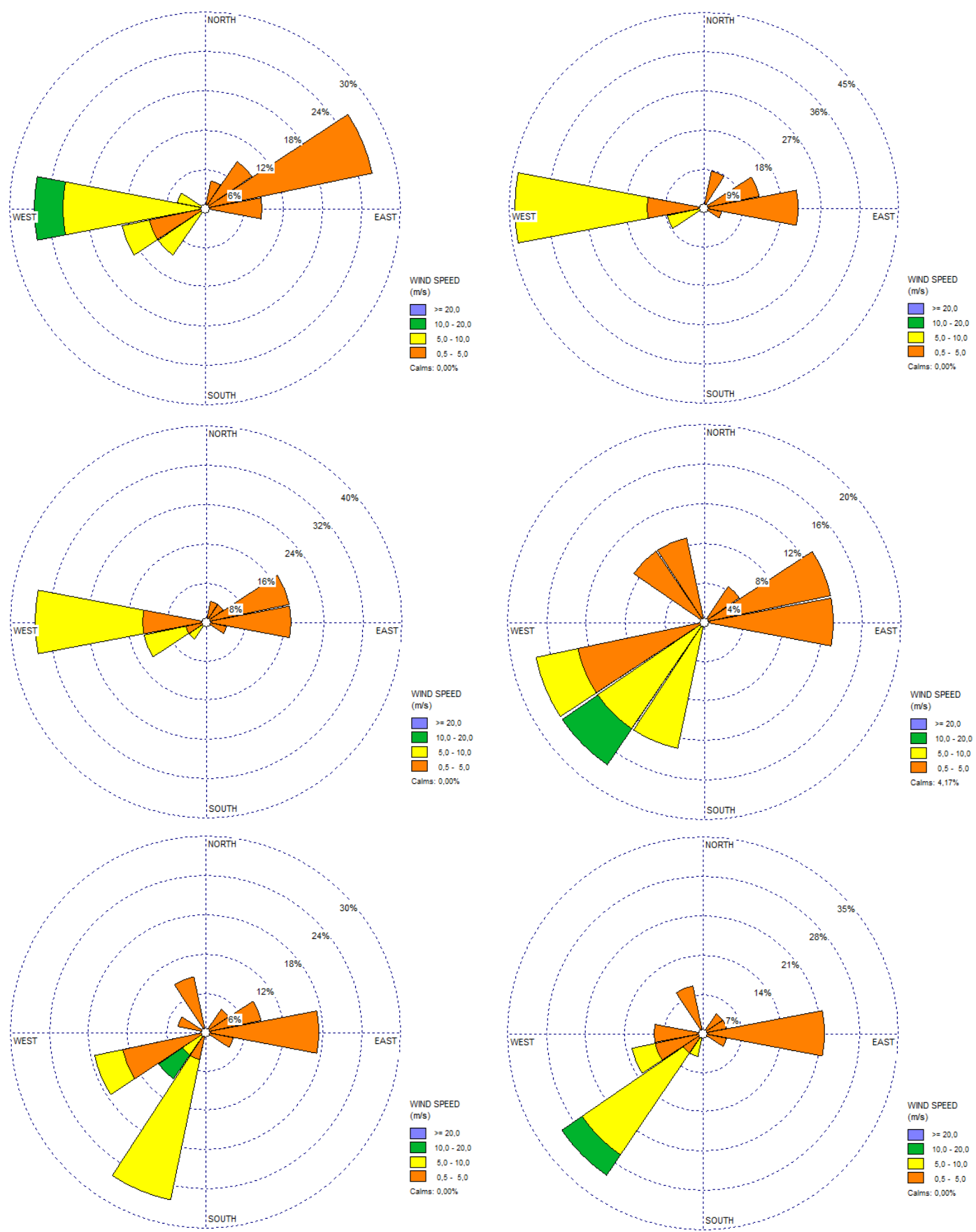

Figure 17. Wind roses on measurement stations of Calama, recorded values above and below the values of the model. On left Colegio Pedro Vergara, in the middle Complejo Deportivo and right Estación Central.

Table 2. Statistical evaluation for the temperature, relative humidity and wind speed, and their benchmark value, for the city of Calama.

\begin{tabular}{ccc} 
Meteorological parameter & Error & Benchmark \\
Temperature & $2.7 \mathrm{~K}$ & $<2.0 \mathrm{~K}$ \\
Relative Humidity & $14.2 \%$ & $<20 \%$ \\
Wind Speed & $2.3 \mathrm{~m} / \mathrm{s}$ & $<2.0 \mathrm{~m} / \mathrm{s}$ \\
\hline
\end{tabular}




\subsubsection{Pollution Analysis}

In Figure 18, we can see a comparison between $\mathrm{PM}_{10}$ concentration values modelled and observed considering both anthropogenic and natural dust sources for the different meteorological stations in the city of Calama.

Observing the values on the stations Colegio Pedro Vergara Keller and Estación Central, we can conclude that the combination of both natural dust and anthropogenic emissions in the area have contributed to the fact that the concentrations values calculated by the model in these two stations adapt with values recorded by the stations properly, with an error of $+2.9 \%$ and $-0.9 \%$ respectively.

In contrast, the concentrations calculated by the model on the station Complejo Deportivo are significantly higher than those recorded by the same stations, with a value of $+47.6 \%$ higher. In this way, the IOA value for the city of Calama for $\mathrm{PM}_{10}$ concentration is 0.6 , giving a value of no perfect forecast, but a not too bad agreement with the observations.

In Figure 19, we identified which weight has the two contributions (natural dust and anthropogenic sources) on the values calculated with the model in the different stations.

Thus we can see that in the city of Calama the contribution of natural dust during the Aeolian dust episode is about $23 \%$ of the total concentration of $\mathrm{PM}_{10}$, being an important value not to attribute all the concentration of particulate from emissions of the mines of the area.

We look at this point the situation of $\mathrm{PM}_{10}$ pollutants in the area. In Figure 20, we can see three maps: on the top we can see the daily value for $\mathrm{PM}_{10}$ if we only consider the contributions of natural dust, which we have calculated from those detailed settings in the Methodology section; on the middle the $\mathrm{PM}_{10}$ daily value for the

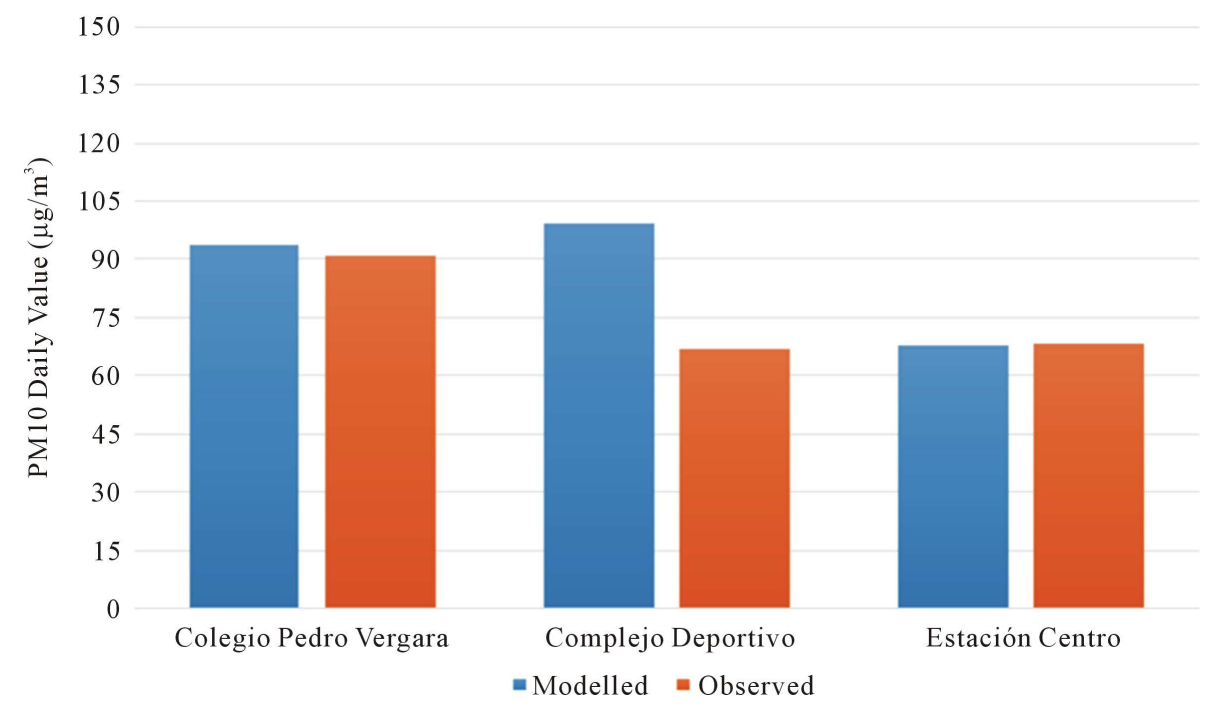

Figure 18. Comparison between daily $\mathrm{PM}_{10}$ values recorded in different stations and the values predicted by the model considering both anthropogenic and natural dust sources.

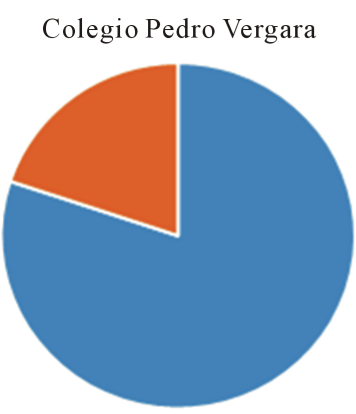

-Anthropogenic "Natural

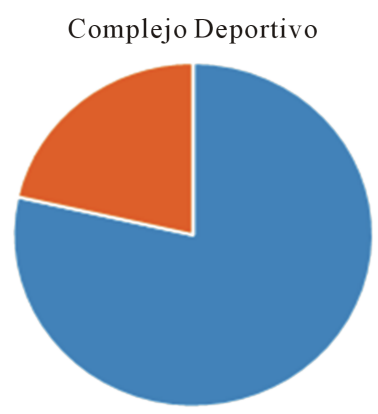

- Anthropogenic " Natural

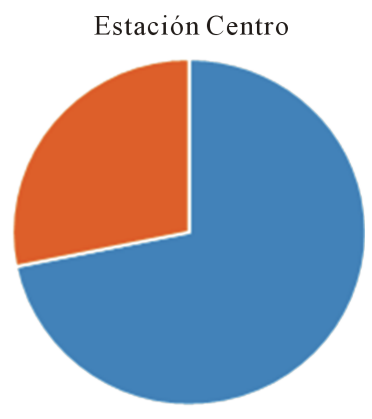

"Anthropogenic "Natural

Figure 19. Contribution for both natural dust and anthropogenic concentration on the measuring stations. 


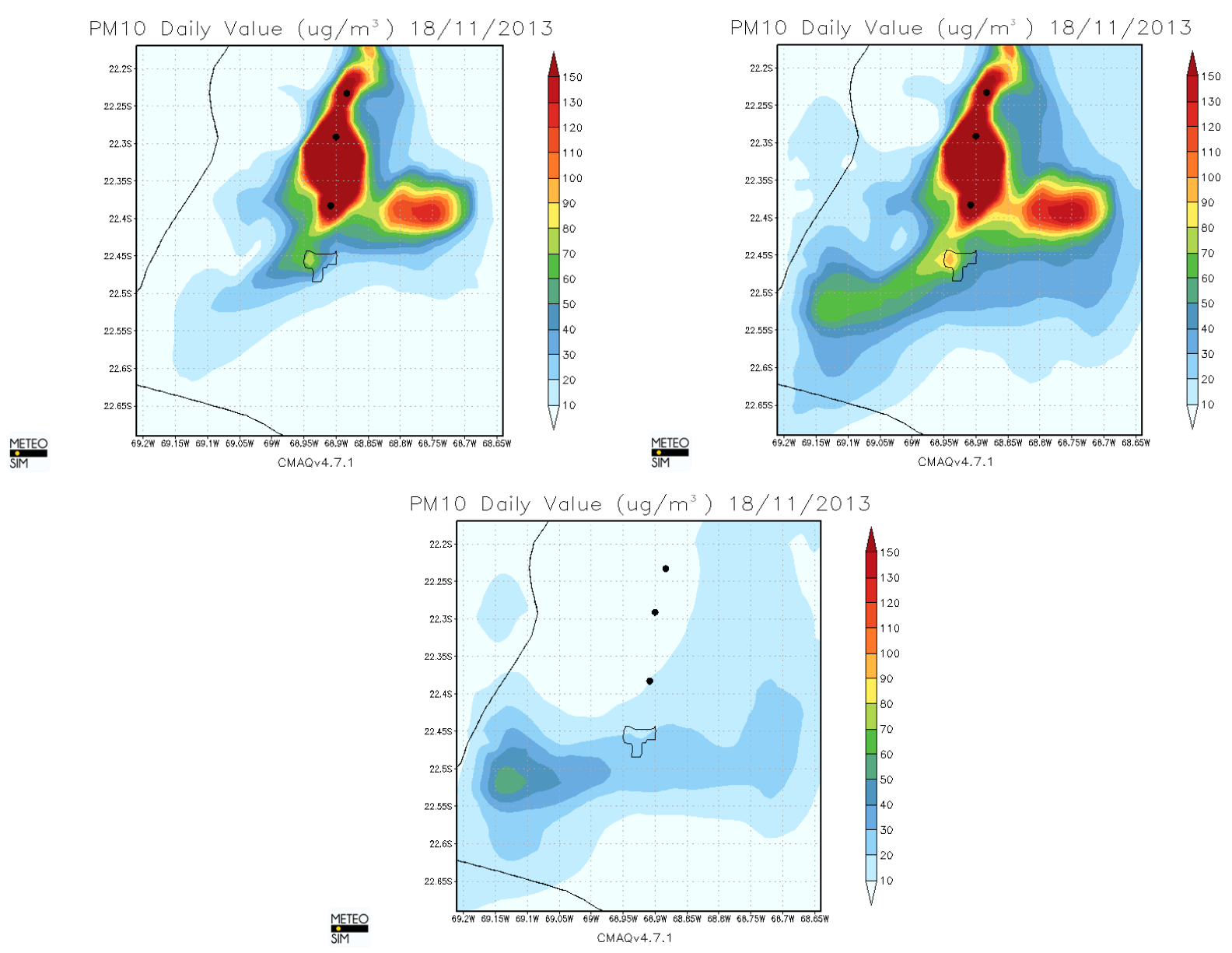

Figure 20. $\mathrm{PM}_{10}$ daily value map for the region of Calama. On top left we can see the $\mathrm{PM}_{10}$ daily value concentration taking into account natural dust contribution, on top right the anthropogenic contribution and on the bottom taking into account both natural dust and anthropogenic contributions.

anthropogenic emissions, also detailed in methodology section; and on the bottom we see the same map of the $\mathrm{PM}_{10}$ daily value, but this time taking into account the contributions of both natural dust and the contributions of anthropogenic emissions of the studied area.

Due the laws of the country against contaminants, is considered an excess of the permitted limit values for $\mathrm{PM}_{10}$ when these exceed $150 \mu \mathrm{g} / \mathrm{m}^{3}$ [34], the same value as Peruvian law. Thus, we can do three tests separately.

The first one is the evaluation of the contributions of natural dust in the area. These are particularly concentrated in the southwest area of Calama, where we detected an important source of erodible material in Figure 4. In turn, this region is affected by winds with moderate intensities to the east-northeast. This causes a concentration of $\mathrm{PM}_{10}$ contributions on southwest of Calama up to $50 \mu \mathrm{g} / \mathrm{m}^{3}$, and values between 30 and $20 \mu \mathrm{g} / \mathrm{m}^{3}$ in the city of Calama, depending on the neighbourhood. Contributions from natural dust have little involvement in the north where the mines are located, with a very low value of daily $\mathrm{PM}_{10}$ concentration, although it slightly affects in neighboring area, so it would be interesting to take this into account where anthropogenic contributions are near from exceedances of the permitted limit values.

We have also calculated the average ratio on the area between the concentration of coarse particulate matter (2.5 - $10 \mu \mathrm{m}$ ) and fine (smaller than $2.5 \mu \mathrm{m}$ ), considering only natural emissions. Thus, it is estimated that the relationship between coarse and fine particles is about $84 \%$ and $16 \%$, respectively. Thus we can determine that the relationship between the two groups of particles has remained approximately constant ( $90 \%$ and $10 \%)$ respect of its emissions.

Furthermore, we have evaluated the contribution of anthropogenic emissions. We can observe that the contributions of the three mines marked on the map are very important, remember, from north to south, Radomiro 
Tomic, Chuquicamata and Ministro Hales, all of them managed by Codelco. We see that their contribution makes the daily values of $\mathrm{PM}_{10}$ concentration in the mining area widely exceed the limit value of $150 \mu \mathrm{g} / \mathrm{m}^{3}$, which would be important to try to take actions to reduce them. Similarly, these anthropogenic contributions also affect the concentration of $\mathrm{PM}_{10}$ on the city of Calama. Finally, the contribution of both sources allows us to observe how it causes a general increase in the concentration of particles in the city of Calama. Due we have several stations throughout the city (Figure 3), we can make a comparative analysis between registered values by the stations and the values predicted by the model.

Near the city of Calama we can find road sections which are very important for the transport of mining equipment to the city of Antofagasta. This route passes through other points of interest such as the communes of Sierra Gorda and Baquedano. Thus, we have chosen a section of the road Ruta 25 and studied the daily evolution of the $\mathrm{PM}_{10}$ concentration (Figure 21), both from anthropogenic and natural dust sources.

We can see in Figure 21 how the value of the concentration of $\mathrm{PM}_{10}$ has a large variation during the day. It is in the early hours when you have the highest values, with a maximum at noon, where they slightly exceed the 80 $\mu \mathrm{g} / \mathrm{m}^{3}$. In this case we see how we have a significant dependence on the height of the planetary boundary layer, obtaining the maximum concentration values when the height is lower, and the concentration values fall rapidly when the height of the planetary boundary layer increases significantly, as is expected. Even the daily concentration value of $27 \mu \mathrm{g} / \mathrm{m}^{3}$ is far from the $150 \mu \mathrm{g} / \mathrm{m}^{3}$ maximum allowable, this remains a major highlight, especially at times of maximum concentration, which may have a significant effect on the visibility, affecting the transport of mining material.

\section{Conclusions}

In the region of Peru, we have been able to simulate the episode of Vientos Paracas. Also, we have calculated the contribution of natural dust caused by wind and with it we have noted that only its contribution already exceeds the allowed limit values of concentration particle at some points in the region. Thus, it will be interesting to adapt the necessary measures for emission sources in the area, such as the transport of mining equipment by road and the management of port of Pisco, where dust contribution reaches a daily particulate matter concentration of $83 \mu \mathrm{g} / \mathrm{m}^{3}$, being its limit value $150 \mu \mathrm{g} / \mathrm{m}^{3}$. Thus, reducing emissions to avoid increasing the concentration values should be the main objective.

The meteorological and air quality validation has allowed us to provide a utility to output data of the model in the area of Chile and we can make more accurate analysis for photochemical model outputs. In the case of Chile,

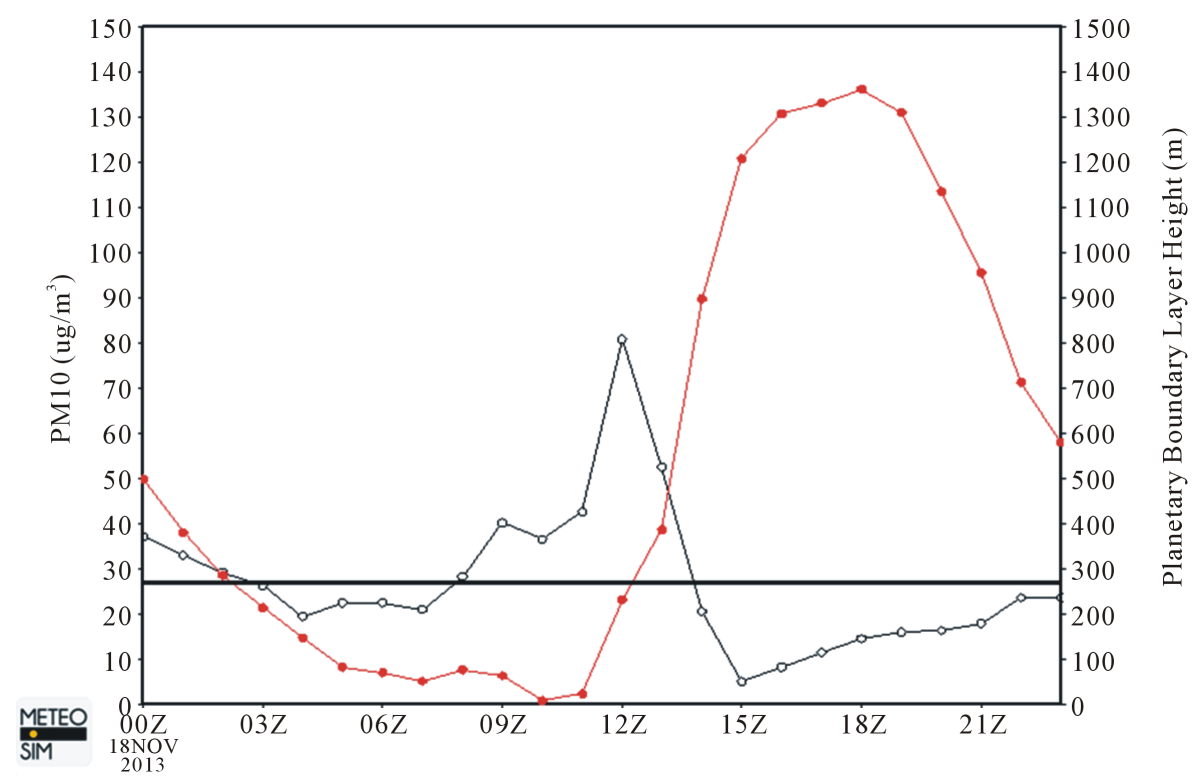

Figure 21. Evolution of $\mathrm{PM}_{10}$ concentration value from anthropogenic and natural dust sources (black) and planetary boundary layer height (red) on Ruta 25. The horizontal black line indicates the daily value for this location. 
even though the contribution of natural dust doesn't reach the concentration values which have been observed in the area of Paracas, we can observe how these have involvement in the city of Calama and the area around where mines are located, such as the mines of Chuquicamata and Radomiro Tomic. Still, we have observed that the most important values of concentration of particles come from anthropogenic sources, especially from the mining area of study, resulting in the city of Calama for the episode selected to have a value of $23 \%$ from natural sources, resulting in an important value not to attribute all particulate pollution to mining emissions.

Finally, we can see that the development of an Eulerian coupled modelling system provides us a tool that allows us to forecast wind-blown mineral dust effects and to discriminate between particulates generated by wind erosion within and outside mines. That way, this tool is useful in the forecast of natural dust contributions in the air, which allows us to make predictions about the limitations on the amount of pollutants that can be emitted by mining industries close to the affected areas, based on weather forecasts. It is also useful in assessing the dust contributions in episodes in which the legislated limit values have been overcome in the past, and in how to distinguish them from other types of emissions. The environmental predictive system has been shown effective in meteorological and air quality forecasting with high accuracy, helping to identify main emission sources and its contribution over air quality levels. This system is a true solution for managing the air quality on mining operation with direct positive impact on the Profit and Loss Statement.

\section{Acknowledgements}

This work has been developed within the framework of Internship Scholarships Santander CRUE-CEPYME in the technological consulting company Meteosim SL. The observations used in the study were obtained from the open access Sistema de Información Nacional de Calidad del Aire that belongs to the Ministerio de Medio Ambiente de Chile.

\section{References}

[1] Brauer, M., Amann, M., Burnett, R.T., Cohen, A., Dentener, F., Ezzati, M., Henderson, S.B., Krzyzanowski, M., Martin, R.V., Van Dingenen, R., van Donkelaar, A. and Thurston, G.D. (2012) Exposure Assessment for Estimation of the Global Burden of Disease Attributable to Outdoor Air Pollution. Environmental Science \& Technology, 46, 652-660. http://dx.doi.org/10.1021/es2025752

[2] Jacobson, M.Z. (2002) Atmospheric Pollution: History, Science and Regulation. Cambridge University Press, New York. http://dx.doi.org/10.1017/CBO9780511802287

[3] EEA (2007) Air Pollution in Europe 1990-2004. EEA Report No 2/2007. European Environment Agency, Copenhagen.

[4] Pope, C.A. and Dockery, D.W. (2006) Health Effects on Fine Particulate Air Pollution: Lines That Connect. Journal of the Air \& Waste Management Association, 56, 709-742. http://dx.doi.org/10.1080/10473289.2006.10464485

[5] Monks, P.S., Granier, C., Fuzzi, S., Stohl, A., Williams, M.L., Akimoto, H., Amann, M., Baklanov, A., Baltensperger, U., Bey, I., Blake, N., Blake, R.S., Carslaw, K., Cooper, O.R., Dentener, F., Fowler, D., Fragkou, E., Frost, G.J., Generoso, S., Ginoux, P., Grewe, V., Guenther, A., Hanson, H.C., Henne, S., Hjorth, J., Hofzumahaus, A., Huntrieser, H., Isaksen, I.S.A., Jenkin, M.E., Kaiser, J., Kanakidou, M., Klimont, Z., Kulmala, M., Laj, P., Lawrence, M.G., Lee, J.D., Liousse, C., Maione, M., McFiggans, G., Metzger, A., Mieville, A., Moussiopoulos, N., Orlando, J.J., O’Dowd, C.D., Palmer, P.I., Parrish, D.D., Petzold, A., Platt, U., Poschl, U., Prevot, A.S.H., Reeves, C.E., Reimann, S., Rudich, Y., Sellegri, K., Steinbrecher, R., Simpson, D., ten Brink, H., Theloke, J., van der Werf, G.R., Vautard, R., Vestreng, V., Vlachokostas, C. and von Glasow, R. (2009) Atmospheric Composition Change: Global and Regional Air Quality. Atmospheric Environment, 43, 5268-5350.

[6] Ki-Hyun, K., Kabir, E. and Kabir, S. (2015) A Review on the Human Health Impact of Airborne Particulate Matter. Environment International, 74, 136-143. http://dx.doi.org/10.1016/j.envint.2014.10.005

[7] Li, J.W., Han, Z.W. and Zhang, R.J. (2011) Model Study of Atmospheric Particulates during Dust Storm Period in March 2010 over East Asia. Atmospheric Environment, 45, 3954-3964. http://dx.doi.org/10.1016/j.atmosenv.2011.04.068

[8] Penner, J.E., et al. (2001) Aerosols, Their Direct and Indirect Effects. In: Houghton, J.T., et al., Eds., Climate Change 2001: The Scientific Basis, Contribution of Working Group I to the Third Assessment Report of the Intergovernmental Panel on Climate Change, Cambridge University Press, Cambridge and New York, 289-348.

[9] Lagos, G. (1997) Impactos ambientales de la minería en Chile. Ambiente y Desarrollo, 4, 13-20.

[10] Ministerio de Energía y minas, República del Perú (2007) Guía para la Evaluación de Impactos en la Calidad del Aire 
por Actividades Minero-Metalúrgicas, Volumen XXI.

[11] Ministerio Secretaría General de la Presidencia (2010) Revisa, reformula y actualiza plan de prevención y descontaminación atmosférica para la región metropolitana, Decreto 66, Norma 1012499.

[12] Saide, P.E., Carmichael, G.R., Spak, S.N., Gallardo, L., Osses, A.E., Mena-Carrasco, M.A. and Pagowski, M. (2011) Forecasting Urban PM10 and PM2.5 Pollution Episodes in Very Stable Nocturnal Conditions and Complex Terrain Using WRF-Chem CO Tracer Model. Atmospheric Environment, 45, 2769-2780. http://dx.doi.org/10.1016/j.atmosenv.2011.02.001

[13] Arasa, R., Lozano, A. and Codina, B. (2014) Evaluating Mitigation Plans over Traffic Sector to Improve $\mathrm{NO}_{2}$ Levels in Andalusia (Spain) Using a Regional-Local Scale Photochemical Modeling System. Open Journal of Air Pollution, 3, 70-86. http://dx.doi.org/10.4236/ojap.2014.33008

[14] Lozano, A. (2015) El papel de las técnicas de modelización en la gestión de la calidad del aire. Agenda de la Empresa, 20.

[15] Arasa, R., Domingo, A. and Vargas, R. (2015) Using a Coupled Air Quality Modelling System for the Development of an Air Quality Plan in Madrid (Spain). Source Apportionment Analysis, Evaluation of Mitigation Measures and Emission Projections. In Progress.

[16] Arasa, R., Picanyol, M., Porras, I. and Solé, J.M. (2013) Integrated Environmental and Meteorological Forecasting and Alert System (SIAM). Proceedings of the Seminar on Air Quality and Meteorological Application for Mining Sector, 4-6 December 2013, Santiago, 44-45.

[17] Romieu, I. and Borja-Aburto, V.H. (1997) Particulate Air Pollution and Daily Mortality: Can Results Be Generalized to Latin American Countries? Salud Pública de México, 39, 403-411. http://dx.doi.org/10.1590/S0036-36341997000500002

[18] Castanho, A.D. and Artaxo, P. (2001) Wintertime and Summertime São Paulo Aerosol Source Apportionment Study. Atmospheric Environment, 35, 4889-4902. http://dx.doi.org/10.1016/S1352-2310(01)00357-0

[19] Bogo, H., Otero, M., Castro, P., Ozafrán, M.J., Kreiner, A., Calvo, E.J. and Martín Negri, R. (2003) Study of Atmospheric Particulate Matter in Buenos Aires City. Atmospheric Environment, 37, 1135-1147. http://dx.doi.org/10.1016/S1352-2310(02)00977-9

[20] Cavazos-Guerra, C. and Todd, M.C. (2012) Model Simulations of Complex Dust Emissions over the Sahara during the West African Monsoon Onset. Advances in Meteorology, 2012, Article ID: 351731.

[21] Skamarock, W.C. and Klemp, J.B. (2008) A Time-Split Non-Hydrostatic Atmospheric Model. Journal of Computational Physics, 227, 3645-3485. http://dx.doi.org/10.1016/j.jcp.2007.01.037

[22] Arasa, R., Picanyol, M. and Solé, J.M. (2013) Analysis of the Integrated Environmental and Meteorological Forecasting and Alert System (SIAM) for Air Quality Applications over Different Regions of the Iberian Peninsula. http://www.harmo.org/Conferences/Proceedings/_Madrid/publishedSections/H15-70.pdf

[23] Byun, D.W. and Ching, J.K.S., Eds. (1999) Science Algorithms of the EPA Models-3 Community Multiscale Air Quality (CMAQ) Modeling System. US Environmental Protection Agency, Washington DC.

[24] Yarwood, G., Rao, S., Yocke, M. and Whitten, G.Z. (2005) Updates to the Carbon Bond Chemical Mechanism: CB05. Final Report Prepared for US EPA. http://www.camx.com/publ/pdfs/CB05_Final_Report_120805.pdf

[25] Carlton, A.G., Bhave, P.V., Napelenok, S.L., Edney, E.O., Sarwar, G., Pinder, R.W., Pouliot, G.A. and Houyoux, M. (2010) Model Representation of Secondary Organic Aerosol in CMAQv4.7. Environmental Science and Technology, 44, 8553-8560. http://dx.doi.org/10.1021/es100636q

[26] Marticorena, B. and Bergametti, G. (1995) Modeling the Atmospheric Dust Cycle: 1. Design of a Soil-Derived Dust Emissions Scheme. Journal of Geophysical Research, 100, 16415-16430. http://dx.doi.org/10.1029/95JD00690

[27] Shaw, W., Allwine, K.J., Fritz, B.G., Rutz, F.C., Rishel, J.P. and Chapman, E.G. (2008) An Evaluation of the Wind Erosion Module in DUSTRAN. Atmospheric Environment, 42, 1907-1921. http://dx.doi.org/10.1016/j.atmosenv.2007.11.022

[28] Ginoux, P., Chin, M., Tegen, I., Prospero, J.M., Holben, B., Dubovik, O. and Lin, S. (2001) Sources and Distributions of Dust Aerosols Simulated with the GOCART Model. Journal of Geophysical Research: Atmospheres, 106, 21562202. http://dx.doi.org/10.1029/2000JD000053

[29] Environmental Protection Agency (2011) Recommendations for the Update of PM2.5 Split Factors. Pacific Environmental Services. http://www.epa.gov/ttn/chief/emch/speciation/

[30] Emery, C. and Tai. E. (2001) Enhanced Meteorological Modeling and Performance Evaluation for Two Texas Ozone Episodes. Final Report Submitted to Texas Natural Resources Conservation Commission, Prepared by ENVIRON, International Corp., Novato.

[31] Santos-Alamillos, F.J., Pozo-Vázquez, D., Ruiz-Arias, J.A., Lara-Fanego, V. and Tovar-Pescador, J. (2013) Analysis 
of WRF Model Wind Estimate Sensitivity to Physics Parameterization Choice and Terrain Representation in Andalusia (Southern Spain). Journal of Applied Meteorology and Climatology, 32, 1592-1609. http://dx.doi.org/10.1175/JAMC-D-12-0204.1

[32] Willmott, C.J. (1981) On the Validation of Models. Physical Geography, 2, 184-194.

[33] Ministerio del Medio Ambiente (2001) Decreto Supremo Nº74-2001-PCM. Reglamento de Estándares Nacionales de Calidad Ambiental del Aire.

[34] Sistema Nacional de Información Ambiental (2013) D.S. N²0/2013 Norma de Calidad Primaria para MP10 Respirable, en especial los valores que definen situaciones de emergencia ambiental. 